\title{
2008
}

\section{Development of an}

\section{Accurate Feed-}

Forward Temperature

Control Tankless

Water Heater

Cooperative Agreement Number:

DE-FC26-05NT42327

Final report to the National Energy Technology Laboratory of the United States Department of Energy.

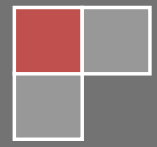


Acknowledgement: This material is based upon work supported by the Department of Energy under Award Number DE-FC26-05NT42327.

\section{Disclaimer:}

This report was prepared as an account of work sponsored by an agency of the United States Government. Neither the United States Government nor any agency thereof, nor any of their employees, nor any of their contractors, subcontractors, nor their employees, make any warranty, express or implied, or assumes any legal liability or responsibility for the accuracy, completeness, or usefulness of any information, apparatus, product, or process disclosed, or represents that its use would not infringe privately owned rights. Reference herein to any specific commercial product, process, or service by trade name, trademark, manufacturer, or otherwise, does not necessarily constitute or imply its endorsement, recommendation, or favoring by the United States Government or any agency, contractor, or subcontractor thereof. The views and opinions of authors expressed herein do not necessarily state or reflect those of the United States Government or any agency thereof. 


\section{Executive Summary}

The following document is the final report for DE-FC26-05NT42327: Development of an Accurate FeedForward Temperature Control Tankless Water Heater. This work was carried out under a cooperative agreement from the Department of Energy's National Energy Technology Laboratory, with additional funding from Keltech, Inc.

The objective of the project was to improve the temperature control performance of an electric tankless water heater (TWH). The reason for doing this is to minimize or eliminate one of the barriers to wider adoption of the TWH. TWH use less energy than typical (storage) water heaters because of the elimination of standby losses, so wider adoption will lead to reduced energy consumption.

The project was carried out by Building Solutions, Inc. (BSI), a small business based in Omaha, Nebraska. BSI partnered with Keltech, Inc., a manufacturer of electric tankless water heaters based in Delton, Michigan. Additional work was carried out by the University of Nebraska and Mike Coward.

A background study revealed several advantages and disadvantages to TWH. Besides using less energy than storage heaters, TWH provide an endless supply of hot water, have a longer life, use less floor space, can be used at point-of-use, and are suitable as boosters to enable alternative water heating technologies, such as solar or heat-pump water heaters. Their disadvantages are their higher cost, large instantaneous power requirement, and poor temperature control.

A test method was developed to quantify performance under a representative range of disturbances to flow rate and inlet temperature. A device capable of conducting this test was designed and built. Some heaters currently on the market were tested, and were found to perform quite poorly.

A new controller was designed using model predictive control (MPC). This control method required an accurate dynamic model to be created and required significant tuning to the controller before good control was achieved. The MPC design was then implemented on a prototype heater that was being developed simultaneously with the controller development. (The prototype's geometry and components are based on a currently marketed heater, but several improvements have been made.) The MPC's temperature control performance was a vast improvement over the existing controller.

With a benchmark for superior control performance established, five additional control methods were tested. One problem with MPC control is that it was found to be extremely difficult to implement in a TWH, so that it is unlikely to be widely adopted by manufacturers. Therefore the five additional control methods were selected based on their simplicity; each could be implemented by a typical manufacturer. 
It was found that one of these methods performed as well as MPC, or even better under many circumstances. This method uses a Feedback-Compensated Feed-Forward algorithm that was developed for this project. Due to its simplicity and excellent performance this method was selected as the controller of choice.

A final higher-capacity prototype heater that uses Feedback-Compensated Feed-Forward control was constructed. This prototype has many improvements over the currently marketed heaters:

- excellent control

- a modular design that allows for different capacity heaters to be built easily

- built-in fault detection and diagnosis

- a secondary remote user-interface

- a TRIAC switching algorithm that will minimize "flicker factor"

The design and engineering of this prototype unit will allow it to be built without an increase in cost, compared with the currently marketed heater. A design rendering of the new product is shown below. It will be launched with a new marketing campaign by Keltech in early 2009.

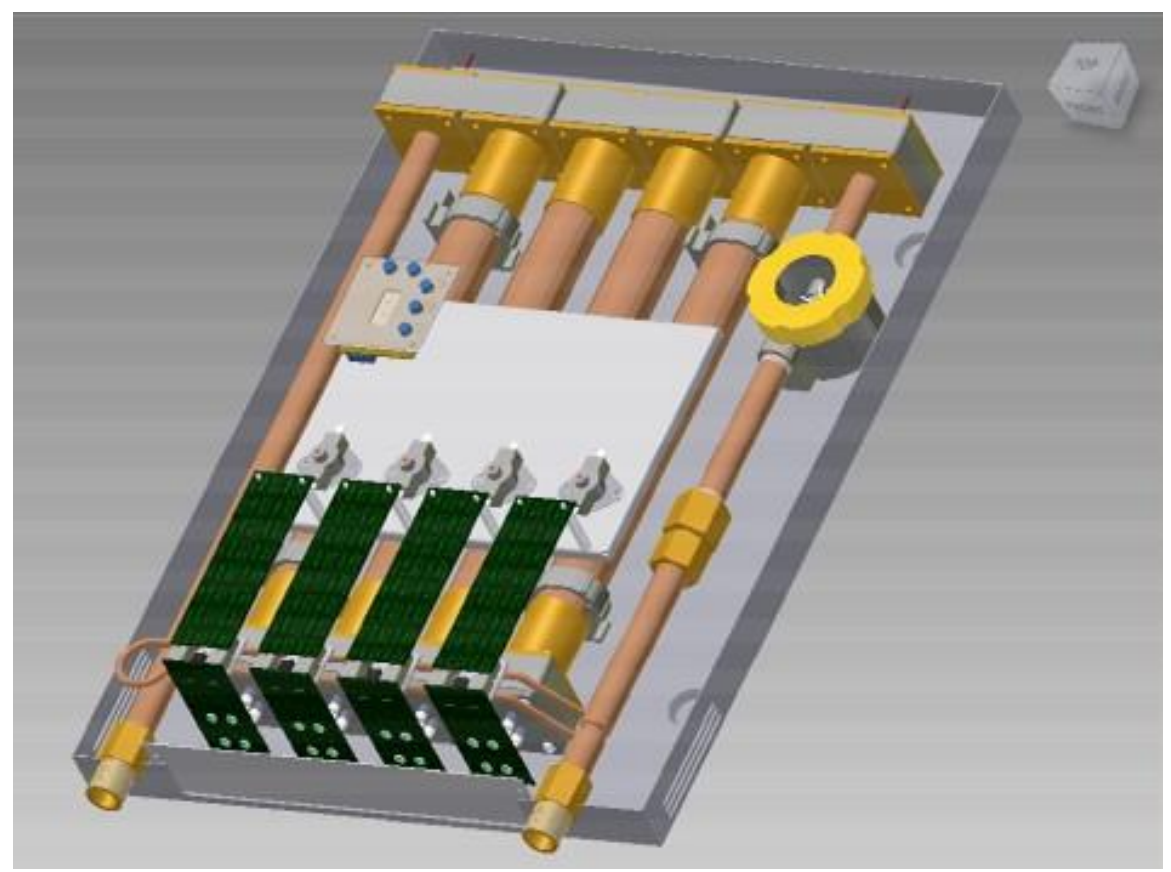




\section{Table of Contents}

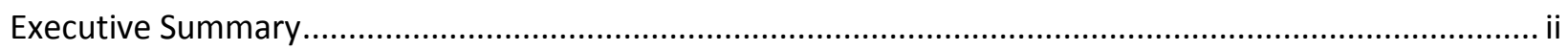

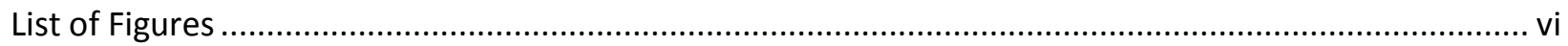

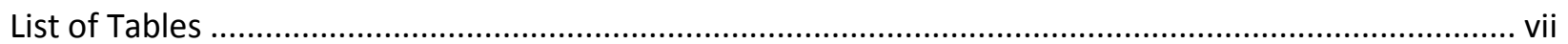

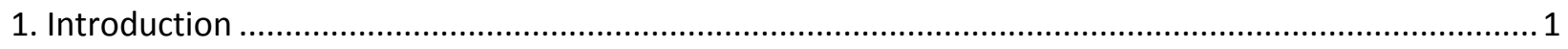

1.1 Rationale for a focus on electric resistance heaters ...................................................................... 1

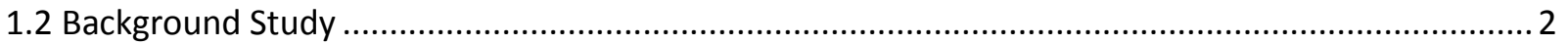

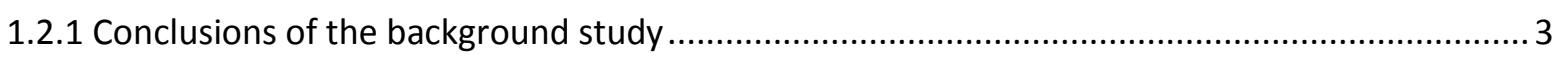

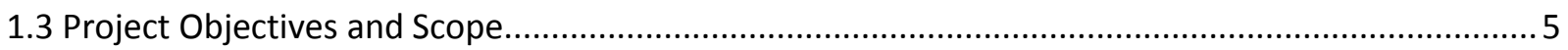

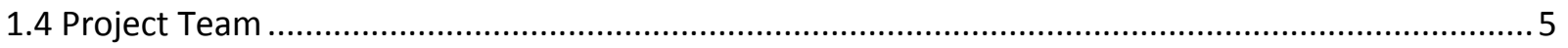

2. Measurement of TWH Temperature Control Performance .............................................................. 7

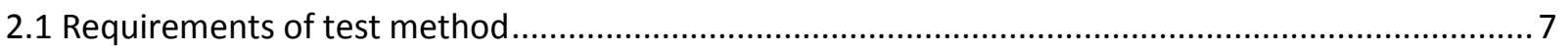

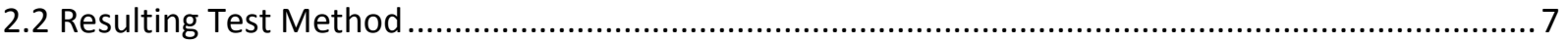

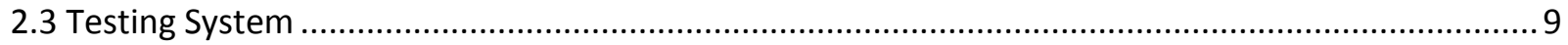

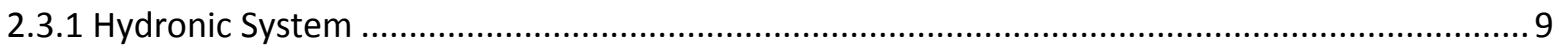

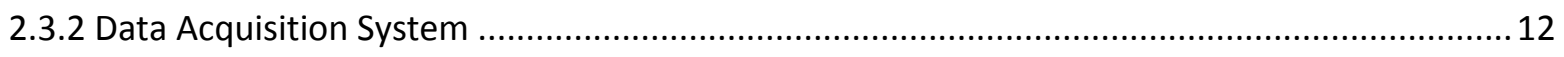

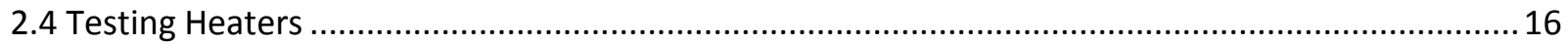

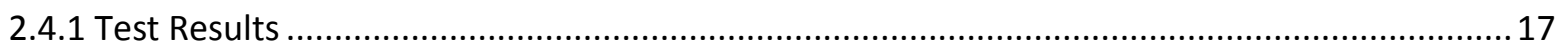

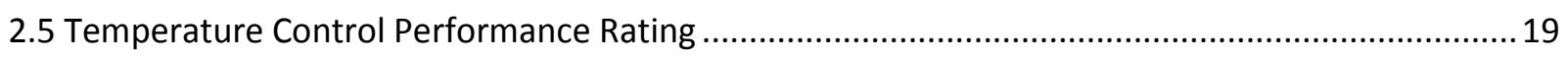

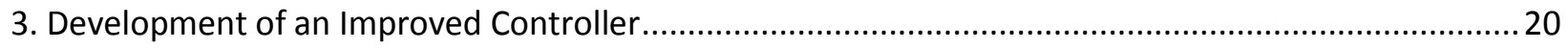

3.1 Technical description of development of MPC for a prototype heater.........................................20

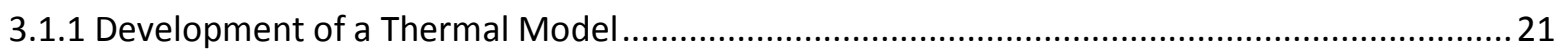

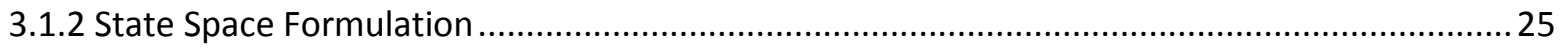

3.1.3 Complete Model of the Tankless Water Heater Assembly ....................................................26

3.1.4 Model Validation and Parameter Estimation ..................................................................... 27

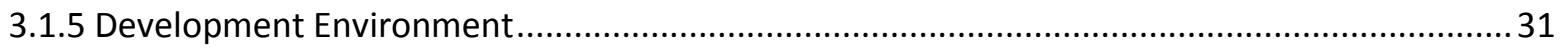

3.1.6 Performance comparison of MPC and existing controller .................................................... 33

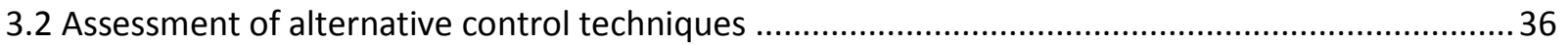

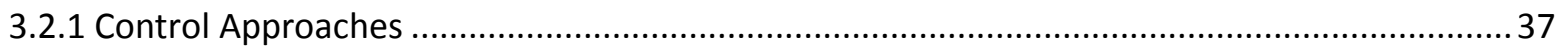

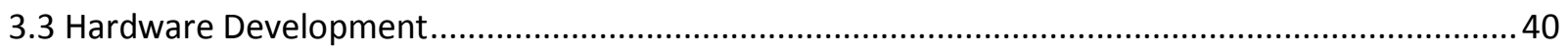




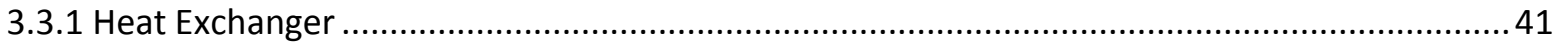

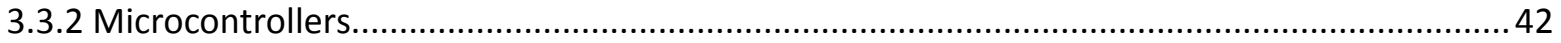

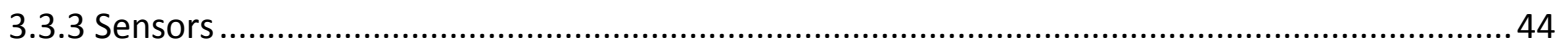

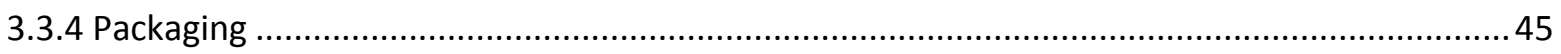

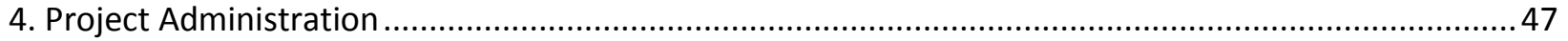

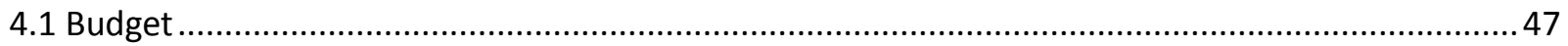

4.1.1 Differences between proposed and actual expenditures.................................................. 47

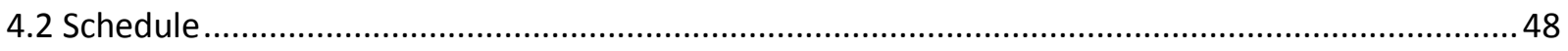

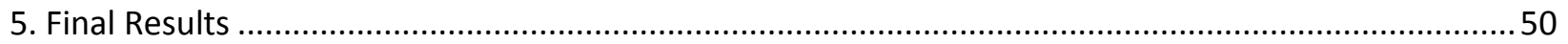

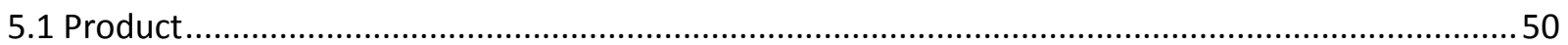

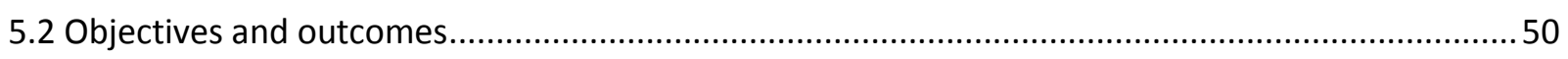

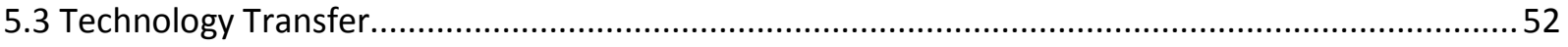

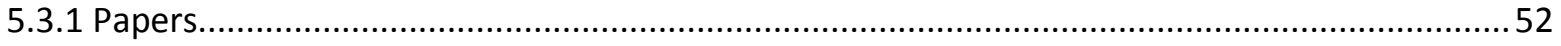

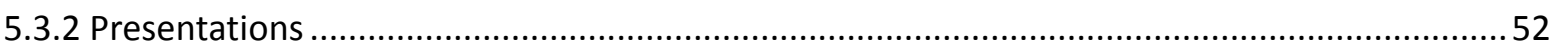

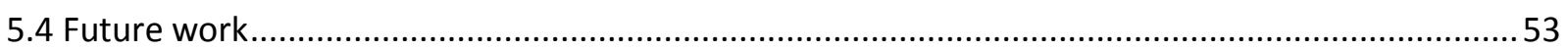

5.4.1 Refinement of the test method to a standard method of test ...............................................53

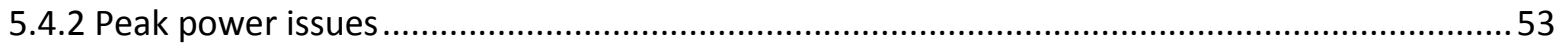

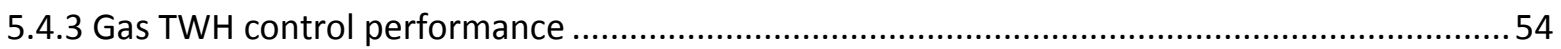

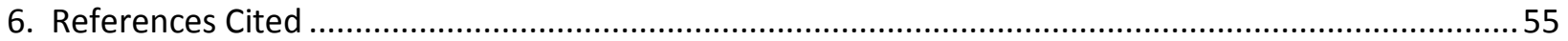




\section{List of Figures}

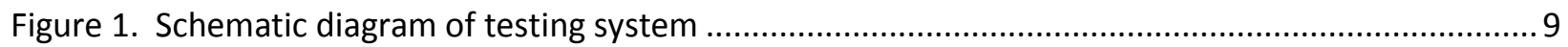

Figure 2: Photo of water carrying portion of test system ................................................................ 12

Figure 3: LabVIEW Data Acquisition Interface ............................................................................ 13

Figure 4: Temperature sensor in-situ calibration ......................................................................... 14

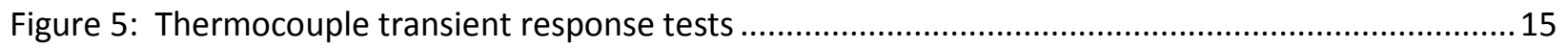

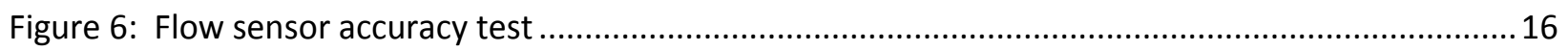

Figure 7: Temperature response of a TWH to a step change in flow rate............................................ 17

Figure 8: Temperature response of another TWH to a step change in flow rate..................................... 18

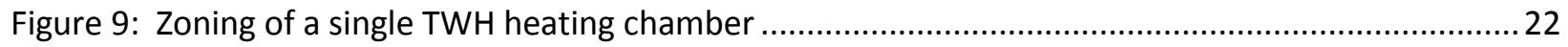

Figure 10: Section through an individual heating chamber ................................................................ 22

Figure 11: Zoning of heating chamber relative to heater element and ambient ....................................23

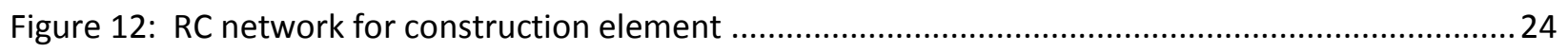

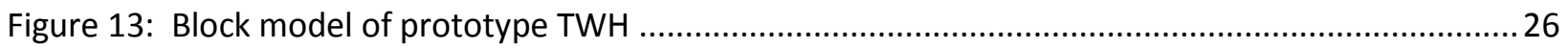

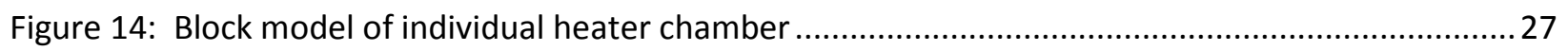

Figure 15: Initial parameter estimation result for training data set ......................................................28

Figure 16: Initial estimated model response and measured result of inlet temperature fluctuation.........29

Figure 17: Hankel singular value decomposition showing relative energy per state ...............................30

Figure 18: Bode diagram comparing full-order with reduced-order model ........................................... 31

Figure 19: Software and hardware setup for rapid controller prototyping and development .................32

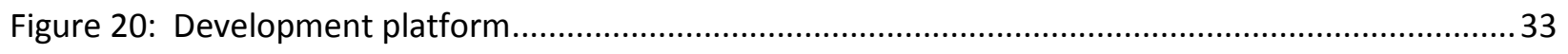

Figure 21: MPC controller performance on test 6 - a cold start with $12 \mathrm{~L} / \mathrm{min}$ flow................................35

Figure 22: MPC and PID performance comparisons ......................................................................... 36

Figure 23: Simulink block diagram of Feedback Compensated Feed Forward Controller.........................40

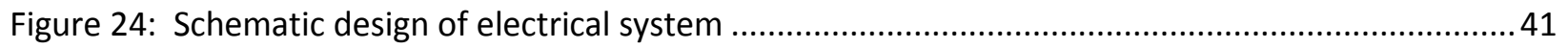

Figure 25: Preliminary prototype heat exchanger ........................................................................ 42

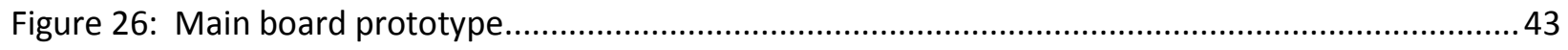

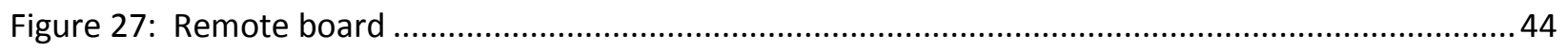

Figure 28: Comparison of production and laboratory flow sensors ..................................................... 45

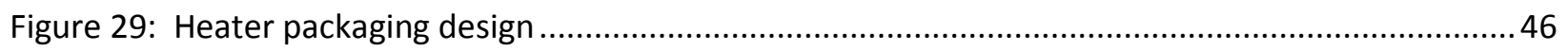




\section{List of Tables}

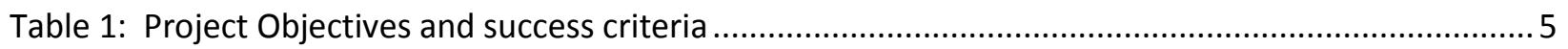

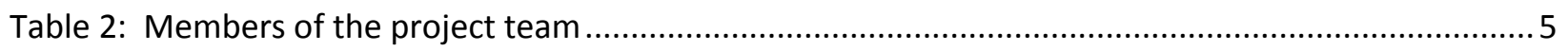

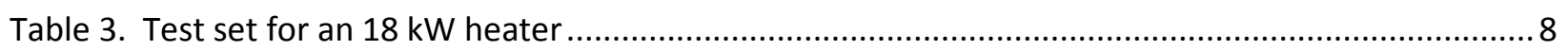

Table 4: ISE results for existing controller and MPC controller ........................................................... 34

Table 5: Summary of ISE results for performance test of seven control approaches ..............................38

Table 6: Total approved budget proposed..................................................................................... 47

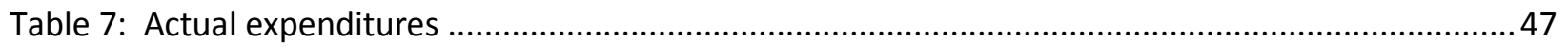

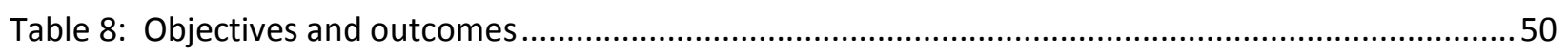

Table 9: ISE results for final (production model) 30 kW TWH ........................................................... 51 


\section{Introduction}

Water heating in homes in the US consumes 1.68 quads $\left(10^{15} \mathrm{Btu}\right)$ of primary energy annually. ${ }^{1}$ Most homes have a tank-type heater, in which water is heated and stored in a tank for later usage. The tanks continually lose heat to the environment, and these losses - referred to as "standby losses" - can be significant. A tankless water heater (TWH) - sometimes referred to as a "demand" or "instantaneous" water heater - doesn't store heated water in a tank. Instead it heats water as it is being used. This virtually eliminates the standby losses associated with tank-type heaters. Despite this benefit, only $1 \%$ of houses in the US ${ }^{2}$ employ TWH as their primary water heating system.

As with most technologies, TWH have both benefits and drawbacks when compared with the status quo technology. One important drawback is that it is difficult to control the outlet temperature in TWH.

This is because the flow rate in a domestic water heating system can change very quickly (such as when an end use is started or stopped) and the system dynamics are inherently non-linear. The purpose of this project is to improve the temperature control of an electric TWH that is currently manufactured and sold in the US, by applying advanced control methods. The rationale is that addressing an important barrier to adoption of TWH will encourage consumers to adopt this energy-saving technology in greater numbers. In the US about 39\% of water heaters use electric resistance heat and $54 \%$ use natural gas [US DOE 2001]. However, the focus of this project is specifically electric TWH.

This report describes the final results of this project. As requested by our sponsor, it does not describe the paths to success or related work previously conducted, and mentions only briefly some of the background work conducted. A review of some of the scientific literature reviewed during this project is included in a paper that presents some findings from this project [Henze et al. 2009].

\subsection{Rationale for a focus on electric resistance heaters}

There are several reasons for the specific focus on electric TWH. One is that the current market for electric resistance heaters is large despite the higher energy costs associated with electricity. Another is that the likelihood of combustion always being a better option than electricity is low. Alternate energy sources such as solar, wind or nuclear can produce electricity, but cannot produce natural gas. Finally, because electric water heaters don't require a flue they are often easier to install in point-of-use

\footnotetext{
${ }^{1}$ Source: Energy Information Administration, 2001 Residential Energy Consumption Survey: Household Energy Consumption and Expenditures Tables.

${ }^{2}$ According to the tables in footnote 1 , out of 111.1 million homes, 1.3 million use tankless water heaters.
} 
applications, where the benefits of reducing piping losses may overcome any disadvantages associated with electricity compared to gas.

The efficiency of electric resistance heating cannot be improved. Thus, the current project is not intended to improve the energy efficiency of the TWH; it is to improve the temperature control performance. The most successful energy conservation projects don't necessarily improve equipment efficiency. Rather, they increase adoption by the public. That is the goal of this project: to eliminate one of the barriers to widespread adoption of an existing technology that uses less energy than the status quo.

One of the most successful energy conservation product development projects in recent times is the development of the compact fluorescent light bulb. However, fluorescent lighting, which is far more energy efficient than incandescent lighting (typical efficacy above 75 lumens/watt compared to around 15 lumens/watt for incandescent), was available for many years before this project. Homeowners would not adopt this technology despite the vast increases in efficiency (and attendant reductions in cooling load). They didn't want to change their fixtures. The compact fluorescent that was developed was less efficacious than the tubular fluorescent lights at the time, but it has saved a tremendous amount of energy by increasing adoption rates. The current project is intended to work in a similar fashion.

\subsection{Background Study}

A comprehensive review of the work previously conducted in the areas related to temperature control was conducted. There are four main reasons for this review: a) to avoid unnecessary duplication of prior work; b) to gain insight into development methods, successful and unsuccessful; c) for guidance on areas that are important to this research, but beyond the scope of this project (such as human perception of temperature variation in showers); d) to discover whether an acceptable solution already exists but isn't being used. Six categories of sources were searched for relevant literature.

1. Manufacturers' data from marketing materials, websites, and personal discussion

2. Codes and Standards from the US and other countries

3. Patents from the US Patent and Trade Office.

4. Scientific articles from a broad range of journals covering areas such as control theory and application, HVAC, thermal sciences, ergonomics, computing, and human physiology.

5. Articles from broad market technical publications such as Popular Science, Heating Piping and Air Conditioning (HPAC), Consumer Reports, and Homebuilder magazine.

6. Reports to governmental agencies, such as Department of Energy, California Energy Commission, and the National Institute of Standards and Technology. 
The information gathered from these sources was reviewed, assessed, and pertinent parts were summarized. (A side note: a great deal of inaccuracy and misperception about TWH was found, particularly in the manufacturers' data, patents, and broad market articles. Technical literature on TWH is unusual in this regard, possibly a result of the immaturity of the TWH market).

\subsubsection{Conclusions of the background study}

There are six main benefits to TWH. These are:

1. Standby savings - this is the energy lost to the environment when the heater is not being used, as compared with a tank-type water heater. The DOE's Office of Energy Efficiency and Renewable Energy (EERE) estimates standby losses to be $8-34 \%$ of the total water heating energy for storage water heaters, depending on water usage patterns and tank insulation.

2. Size - tankless water heaters take up very little space, and can be hung on a wall. For homes with a high cost-per-area ratio $\left(\$ / \mathrm{ft}^{2}\right)$ this can be a significant factor, often more significant than the higher first cost of the TWH. Furthermore, the smaller size allows point-of-use tankless water heaters to be used in applications that wouldn't allow a tank, such as under a sink.

3. Durability - the most common cause of water heater replacement - tank failure - doesn't occur in TWH, so they tend to last much longer: 20 years, versus 13 years for tank-type heaters.

4. Continuous Hot Water Supply - the TWH can be used at capacity for multiple events in series, such as multiple morning showers, without a decrease in supplied temperature.

5. Distributions Savings - this is normally overlooked and wasn't discussed anywhere in the literature, but is significant. "Distribution loss" refers to the heat lost by hot water in the pipes that distribute it through a home or building. These losses are significant, typically $10-20 \%$ and up to $50 \%$ of water heating energy [ASHRAE 2007, Hiller 2005], and they can be reduced with tankless water heaters. This reduction is brought about by reducing the supply temperature, and mixing less cold water at the point of use.

In a tank-type heater reducing the supply temperature reduces the capacity of the water heater, but this is not the case with TWH. Another reason that tank-type heaters are kept at higher temperatures is to reduce growth rate of legionella bacteria in the tank [ASHRAE 2007]. Since TWH do not store hot water they do not have this problem to the same extent as tank-type heaters. Achieving these supply-temperature-related savings requires very good temperature control.

6. Special Applications - many emerging technologies can produce heated water far more sustainably than current technologies, but are not widely adopted because of first cost or reliability. These technologies can be enabled by integrating them with TWH boosters. Current 
examples include solar water heaters and heat pump water heaters. However, booster applications require very good temperature control.

There are three main drawbacks to TWH that keep them from being more widely adopted by US consumers. These are:

1. Large power requirement - since the water must be heated very quickly, a great deal of power must be added to the flow stream. For a whole house application, $30 \mathrm{~kW}$ or more may be needed. This requires larger electrical equipment than is commonly used in US homes. Some electric utilities have expressed concern over the potential for higher peak loads on neighborhood transformers. However, electric TWH can be an excellent application of a load limiting device, in which a current transformer can be placed on the service entrance and the TWH power reduced if the total load nears capacity. We conceived of this idea during this project, but found that it has already been patented by a TWH manufacturer. Furthermore, a study by Johnson and Clark [2006] shows that the peak load of a small number of TWHequipped homes is identical to tank-equipped homes because of load diversity. These issues are discussed further in section 5.4.2.

2. Higher first cost - a TWH is typically about $\$ 700$ more to purchase than a tank-type heater. Also, the additional power capacity may bring about higher installation costs. However, it seems likely that this is a result of an immature market. If TWH were produced in the same quantity as storage heaters it seems likely that their smaller size would cause them to be similarly priced, since they require much less material, are easier to ship and store, and can be carried into a house by one installer.

3. Difficult to control - the poor temperature control of existing TWH in the market is one of the factors that slows the adoption rate. Real estate developers know that a comfort issue is likely cause a homebuyer to complain, whereas higher energy consumption is not. In European and Asian markets, users are less sensitive to sacrifices in comfort and accept greater temperature swings in their shower water [Herrmann et al. 1994, Ohnaka et al. 1994, Rohles and Konz 1982]. This has allowed fairly high adoption rates, but until control is improved, American consumers are unlikely to adopt TWH in large scale.

One of the difficulties of control is that there are no currently existing standards, guidelines or methods to describe the control performance of TWH and rate it. This leaves developers without guidance when trying to improve control. For example, is it better to have a $10^{\circ}$ overshoot for 1 second, or a $5^{\circ}$ overshoot for two seconds? Is it better to have a short term overshoot or a long term offset error? Furthermore, few developers are able to measure and characterize performance, and this means that it is difficult for them to improve performance because any changes they make may or may not improve control. 


\subsection{Project Objectives and Scope}

The objective of this project is to develop an improved controller for an existing electric TWH. This controller should give superior temperature control performance without imposing a significant cost premium. Based on the discussion of drawback \# 3 in section 1.2.1, it is also necessary to develop a method by which to test and rate the temperature control performance of TWH. Finally, for the work in this project to be useful, the controller must be adopted into a product that is manufacturable for sale to the US public, and the work must be described and made available to the public so that other manufacturers and developers can take advantage of it.

These objectives and criteria for evaluating successful completion of them are summarized in Table 1 below.

Table 1: Project Objectives and success criteria

\begin{tabular}{ll}
\hline Objective & Criterion for success \\
\hline Develop a test method & Ability to quantify control performance \\
Develop a rating system & Ability to meaningfully quantify better performance \\
Develop an improved TWH controller & A working controller that improves control \\
Include controller in manufacturable prototype & A prototype that is ready for mass production \\
Impose minimal cost premium & Increase overall cost by $<5 \%$ \\
Disseminate results & Published papers or public presentation
\end{tabular}

\subsection{Project Team}

The project team was made up of several highly motivated individuals with a keen interest in the success of this project. The members of this team are shown below in Table 2 .

Table 2: Members of the project team

Department of Energy

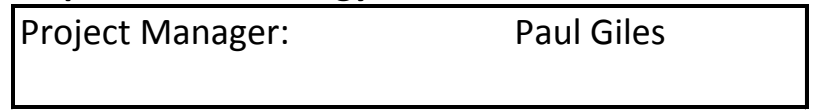

Building Solutions, Inc.

\begin{tabular}{|ll|}
\hline Principal Investigator: & Grenville Yuill \\
Project Manager and Co-PI: & David Yuill \\
Research Scientist: & Andrew Coward \\
\hline
\end{tabular}

Subcontractors

\begin{tabular}{|ll|}
\hline Keltech, Inc.: & Ken Lutz \\
University of Nebraska: & Gregor Henze \\
Consultant: & Mike Coward \\
\hline
\end{tabular}


Building Solutions, Inc. (BSI) is a small business based in Omaha, Nebraska, who specialize in engineering and scientific research of heating, ventilation and air-conditioning related topics, with a special focus on energy conservation. The company was formed in 2003 and is headed by David Yuill. Dr. Grenville Yuill is a part-time employee of BSI and was the principal investigator in the project's proposal. Near the outset of the project he accepted an upper-level administration job at the University of Nebraska, the demands of which prevented him from contributing significant effort to the current project. Therefore, David Yuill took over the role of principal investigator.

For this project Building Solutions, Inc. partnered with Keltech, Inc., a manufacturer of electric tankless water heaters. Keltech was founded in 1987 by Ken Lutz, and now produces over 80 models of TWH for many different applications: residential, commercial, industrial (process water heating), safety shower, emergency eyewash, aircraft and non-water fluid heating. Their standard heaters range in size from 5 to $144 \mathrm{~kW}$. They specialize in highly durable, carefully constructed water heaters made with the fewest possible imported parts, and in customized heater designs for special applications. They have four current patents on their TWH technology and several more patents in process. Keltech has 15 employees at its factory in Delton, Michigan.

Some of the controls modeling and algorithm development was subcontracted to Dr. Gregor P. Henze, $\mathrm{PE}$, an associate professor at the University of Nebraska's Architectural Engineering Program.

Some of the microcontroller prototype development work was subcontracted to Michael Coward, cofounder of Continuous Computing, a multinational computer hardware and software producer headquartered in San Diego, California. 


\section{Measurement of TWH Temperature Control Performance}

As described above, a method of measuring and assessing temperature control performance in electric TWH is needed, but doesn't exist in the literature. Such a method was required for this project, so a method was developed and a testing system was built to conduct the tests. There were many substantial refinements to the test method and to the testing system, based on our experience testing commercially available electric TWH. Only the final method, test system, and rating system are presented here.

\subsection{Requirements of test method}

Repeatable - The test method must be repeatable, not only by us but by other researchers or developers. This is a basic requirement of any valid scientific study. It should be possible for results to be duplicated so that others can verify their accuracy. Ideally, it should be possible for the test method to be used by developers and manufacturers so that they may benefit from this work. This will contribute to improvement of temperature control throughout the industry - a central goal of this project.

Applicable - The test method must measure the type of performance that is applicable to human comfort. Therefore, measurement accuracy levels finer than those that humans can detect in showers are unnecessary. Similarly, test conditions that do not occur in residential service water heating applications are also unnecessary.

Inclusive - The test method must be "as simple as possible, but not simpler" (to quote Albert Einstein). The goal, therefore, is to use the minimum number of tests that still manage to fully capture the myriad different types of control performance shortcomings that would affect residential users.

Understandable - Results gathered from early versions of the test (prior to refinements that significantly condensed the test procedure) contained a huge number of data of many categories. Comparing these results for two different TWH controllers was difficult or impossible. Therefore, the test method must contain a way to distill the important control performance features into a compact form, for easy comparison of different TWH controllers.

\subsection{Resulting Test Method}

The final test method consists of 11 separate tests for a given heater. Each of these tests involves a step change to either flow rate or inlet temperature. During the flow rate change the heater is raising the water temperature by $30^{\circ} \mathrm{C}$. There are seven step changes to flow rate: increases and decreases of 
various magnitudes. These flow rates are selected based upon the heater's power capacity. The maximum flow rate used in the test should not require more than $90 \%$ of the heater's power when raising the water by $30^{\circ} \mathrm{C}$. This is calculated with a steady-state energy balance (a simplified First Law of Thermodynamics statement):

$$
Q=\dot{m} \cdot c_{p} \cdot \Delta T
$$

where $Q$ is the heater power $(\mathrm{kW}), \dot{m}$ is mass flow rate of water $(\mathrm{kg} / \mathrm{s}), c_{p}$ is the specific heat of water $(4.18 \mathrm{~kJ} / \mathrm{kg}-\mathrm{K})$, and $\Delta T$ is the temperature rise $\left(30^{\circ} \mathrm{C}\right.$, or $\left.30 \mathrm{~K}\right)$.

For the $18 \mathrm{~kW}$ heater that was used as a development prototype in this project, the flow rate can be determined by rearranging the equation above and substituting values:

$$
\dot{m}=\frac{0.9 \times 18 \mathrm{~kW}}{\left(4.18 \frac{\mathrm{kJ}}{\mathrm{kg} \cdot{ }^{\circ} \mathrm{C}} \cdot 30^{\circ} \mathrm{C}\right)}=0.13 \frac{\mathrm{kg}}{\mathrm{s}} \text { or } 8 \mathrm{~L} / \mathrm{min}
$$

This means that the flow rate basis is $8 \mathrm{~L} / \mathrm{min}$, and all test flow rates are $1 / 4,1 / 2$ or $3 / 4$ of this value.

Besides the seven step changes to flow rate there are also four step changes to inlet water temperature. These step changes have fixed magnitude of $5^{\circ} \mathrm{C}$ and $15^{\circ} \mathrm{C}$ in both increasing and decreasing temperatures. During these tests, the flow rate is kept constant at $1 / 2$ of the basis flow rate, as determined above.

The resulting test set for an $18 \mathrm{~kW}$ heater is summarized in Table 3 below.

Table 3. Test set for an $18 \mathrm{~kW}$ heater

\begin{tabular}{c|cc|}
\cline { 2 - 3 } & \multicolumn{2}{|c|}{ Flow Rate [L/min] } \\
Test \# & Initial & Final \\
\cline { 2 - 3 } 1 & 2 & 8 \\
2 & 8 & 2 \\
3 & 4 & 8 \\
4 & 8 & 4 \\
5 & 0 & 2 \\
6 & 0 & 4 \\
7 & 0 & 8 \\
\cline { 2 - 3 }
\end{tabular}

\begin{tabular}{|c|c|}
\cline { 2 - 2 } & $\begin{array}{c}\text { Temperature Step } \\
{\left[{ }^{\circ} \mathrm{C}\right]}\end{array}$ \\
\cline { 2 - 2 } 8 & 5 \\
9 & -5 \\
10 & 15 \\
11 & -15 \\
\cline { 2 - 2 } &
\end{tabular}




\subsection{Testing System}

A device was constructed and modified until it was able to successfully carry out the tests required in the test method. This device controls the flow and inlet water temperature very steadily and accurately, using a complex system of valves, and allows for very crisp step changes to these parameters. It has a data acquisition system that accurately senses: temperature at four locations; water flow rate; and electrical power used by the TWH. These quantities are logged at high frequency and can be monitored in real time by the operator. Each of the sensors in this system was calibrated (NIST traceable) by the manufacturers, and the calibration was verified when the sensor was installed in the test system.

\subsubsection{Hydronic System}

The hydronic system is shown schematically in Figure 1 below. A discussion follows that is intended to describe the system sufficiently so that other researchers or developers may use it to construct their own testing system with minimal effort.

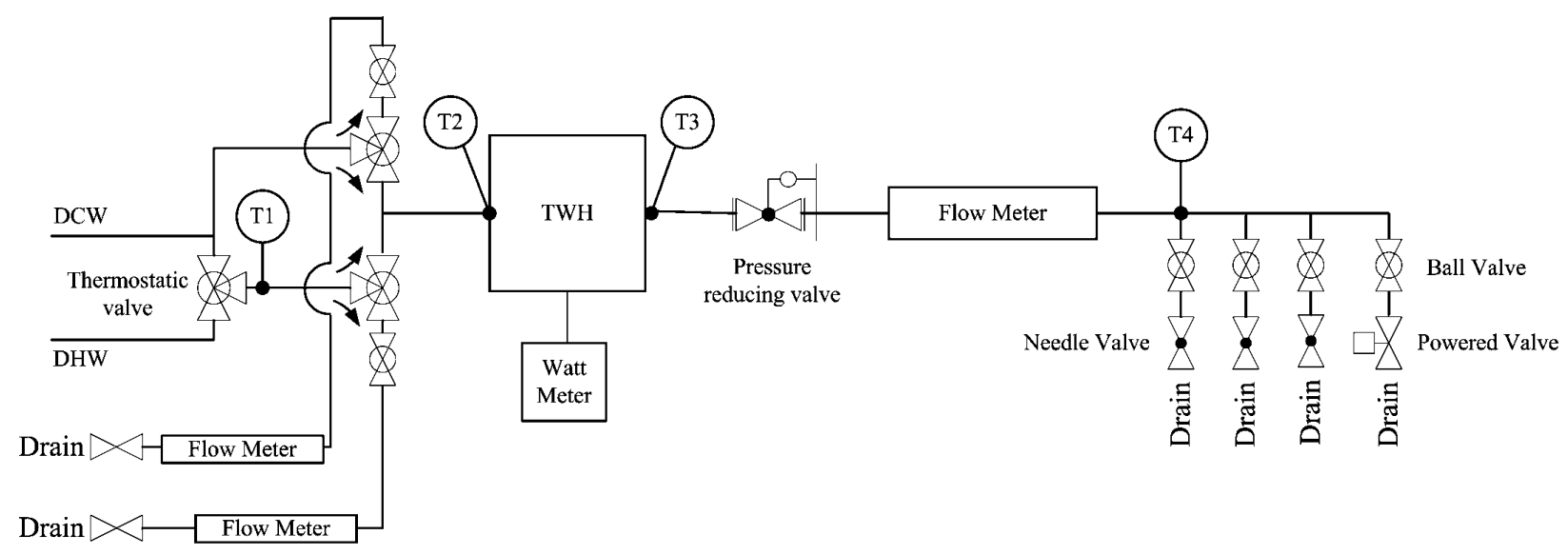

Figure 1. Schematic diagram of testing system

a. Starting from the upper left of Figure 1 the water enters from the domestic cold water (DCW) and hot water (DHW) lines, which are connected to city water. The DHW line is connected to a tank-type water heater with $60^{\circ} \mathrm{C}\left(140^{\circ} \mathrm{F}\right)$ water in it. A thermo-regulating valve mixes cold and hot water and the first temperature sensor, $\mathrm{T} 1$, senses this mixed water temperature. The purpose of this mixing is to maintain the nominal hot water at constant temperature (slightly below $60^{\circ} \mathrm{C}$ ).

b. From this point the hot water enters a diverting valve where it is either mixed with cold water (upwards) or dumped (downwards). The purpose of dumping is that the flow rate through the hot water supply piping must be constant because of inevitable heat loss (if the hot water was not dumped, it would cool off in the pipe upstream of the thermostatic valve prior to the start 
of the test). Similarly, the cold water is also either mixed or bypassed. Both cold and hot water lines are insulated.

c. The bypass side of the diverting valve, where the dumped water passes, has a rough-grade flow sensor and a needle valve on it. The valve is used to balance the system so that the pressure loss through the test system is the same as the pressure loss through the bypass line. This helps protect the system from pressure fluctuations, which could affect temperature in an unbalanced system. The flow sensor indicates whether the valve is succeeding in balancing the system.

d. The two diverting valves, shown in the figure with a pair of small curved arrows beside them, mix the hot and cold water together, and it enters the test heater at the point marked " $\mathrm{T2}$ " on Figure 1 ( $\mathrm{T} 2$ is temperature sensor 2). Care must be taken to ensure sufficient flow disturbance in this section so that stratification does not occur. Stratification can damage the accuracy of the temperature measurement at $\mathrm{T} 2$.

e. After passing through the test heater the temperature is measured by T3. Significant stratification is also possible here, but it is important to measure the outlet temperature as close to the outlet as possible. Again, care must be taken in selection of the location for the outlet temperature sensor. Also, if the temperature sensor is very thin (which is necessary in order to have a short thermal time constant) and not well supported, it may oscillate in the flow stream's turbulence, and in doing so make thermal contact with the pipe walls for brief periods. This will affect results, but may go unnoticed.

f. A pressure reducing valve reduces the pressure that the flow control valves downstream will experience. This prevents fluctuations in the supply water pressure (city water) from affecting the flow rate (whereas the discussion of a balanced system, above, addresses pressure fluctuation effects on inlet temperature).

g. Next, a laboratory-grade turbine flow sensor supplies high frequency flow measurements to the data acquisition system. This sensor must be selected to be able to accurately measure hot water. It is located downstream of the heater because flow sensors typically require a long undisturbed inlet and exit condition (i.e. no fittings or bends nearby). A long length of pipe upstream would lose heat to the environment, whereas downstream this heat loss doesn't affect any measurements.

h. A fourth temperature sensor, T4, is located downstream of the flow sensor. This was used for informal experiments to determine piping effects on heat loss and damping of temperature fluctuations, but is not required for typical control performance testing.

i. Finally, four sets of valves are piped in parallel. Each set consists of a needle valve and a ball valve connected in series. These valves control the flow rate. They allow step changes to be 
imposed on the system, from one controlled flow rate to another. To illustrate the rationale behind these four sets of pipes, an example is used.

Consider a step from $4 \mathrm{~L} / \mathrm{min}$ to $8 \mathrm{~L} / \mathrm{min}$. To prepare for this step, open ball valve 1 (others closed) and adjust needle valve 1 until $8 \mathrm{~L} / \mathrm{min}$ is attained. Then close ball valve 1 and open ball valve 2 . Adjust needle valve 2 until $4 \mathrm{~L} / \mathrm{min}$ is attained. Now, start the test, gathering data until the system is stable with $4 \mathrm{~L} / \mathrm{min}$ of flow. Once the system is stable, simultaneously close ball valve 2 while opening ball valve 1 . This provides the desired step, with the instant of the switch being defined as $t=0$.

The fourth (rightmost) set of valves in Figure 1 has an actuated valve. This valve was calibrated with the data acquisition system so that accurate and repeatable ramp changes to flow rate could be achieved. However, our experience testing and analyzing multiple heaters suggests that the ramp changes are not necessary; they do not increase the ability to characterize good control appreciably. Furthermore, they do not mimic typical conditions in a residential hot water system as well as step changes.

The use of actuators for the ball valves was considered. It was concluded that a technician can provide a reliable and sufficiently crisp step (rapid simultaneous opening and closing of valves), and that automation of this process would not reduce technician time for a set of tests. Therefore, automated valves are not recommended.

j. Finally, downstream of these valve sets the system drains into a large pipe that is open to air pressure.

Copper pipe (nominal $1 / 2$ ") is used for most of the system. Although rubber and synthetic hose have lower overall heat conductivity, they have higher thermal mass for a given length, compared with copper (because the specific heat of copper is much lower). Thus there is a trade-off between steady and transient response associated with the choice of hose or pipe.

A photograph of the hydronic portion of the test system is shown in Figure 2. In the photo a commercially available TWH (with its cover removed) is mounted on the upper part for testing. This system is mounted on a wheeled lightweight frame. 


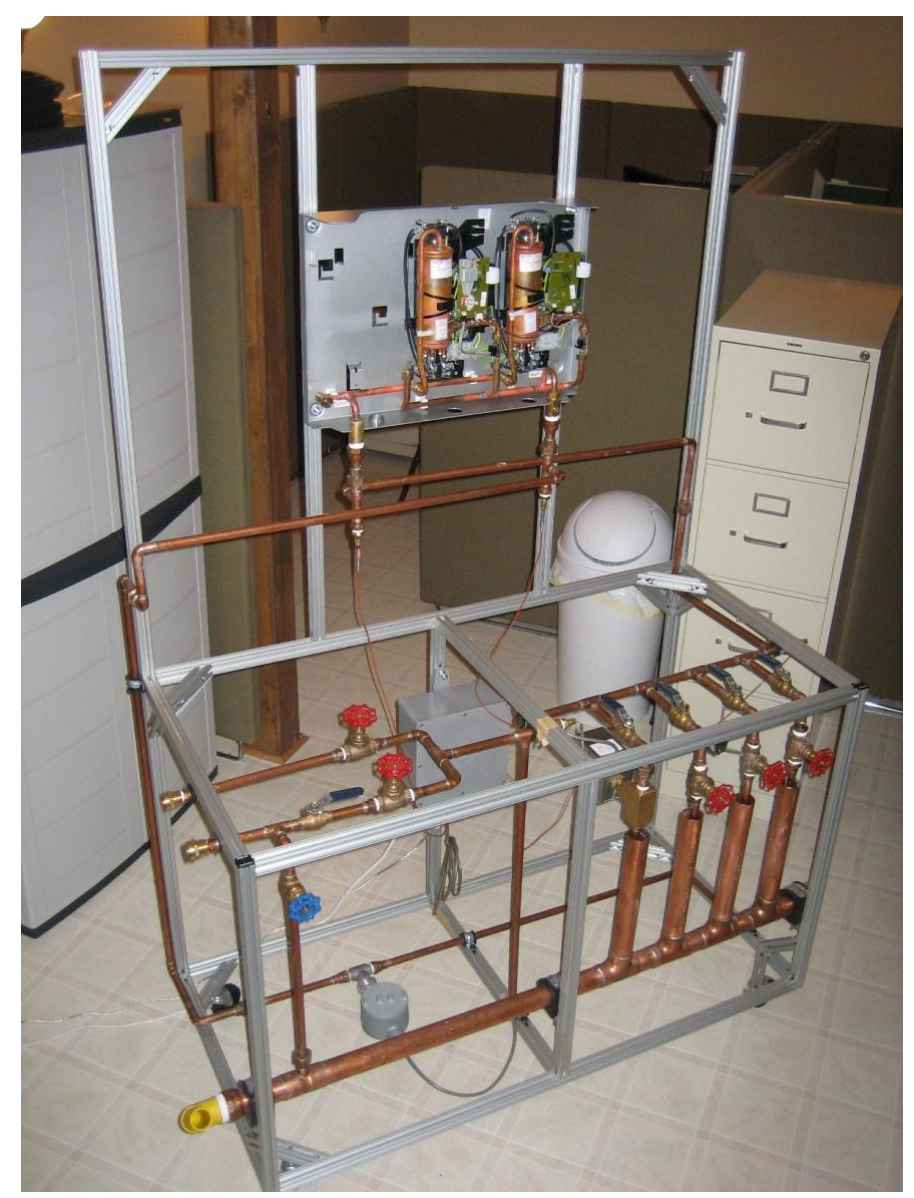

Figure 2: Photo of water carrying portion of test system

\subsubsection{Data Acquisition System}

The data acquisition system (DAQ) consists of a software human interface, a hardware interface and several sensors.

\subsubsection{Software interface}

LabVIEW software and an SCC signal conditioner (both produced by National Instruments) were used to collect and store data. A LabVIEW interface was developed, as shown in Figure 3. Four temperatures are shown in real time (thermometer-style, with digital readouts below them), a flow sensor, and electric power. These values are also plotted on a sub-screen in real-time. The use of such real-time monitoring is highly recommended because it illuminates many kinds of problems that naturally occur in such testing, and because it allows the technician to know when steady-state has been reached, so the test can be started. 
In the upper right of the figure a box encloses the actuated valve, discussed in point i. of 2.3.1, above. Start Flow, End Flow and ramp time can be entered, then started by clicking "start". Clicking "Manual" causes the dial on the left, or the digital entry field below it, to control the flow through this valve.

Finally, "Record" and "New File" buttons (left, middle) cause the measured data to be recorded in the current file or a new file.

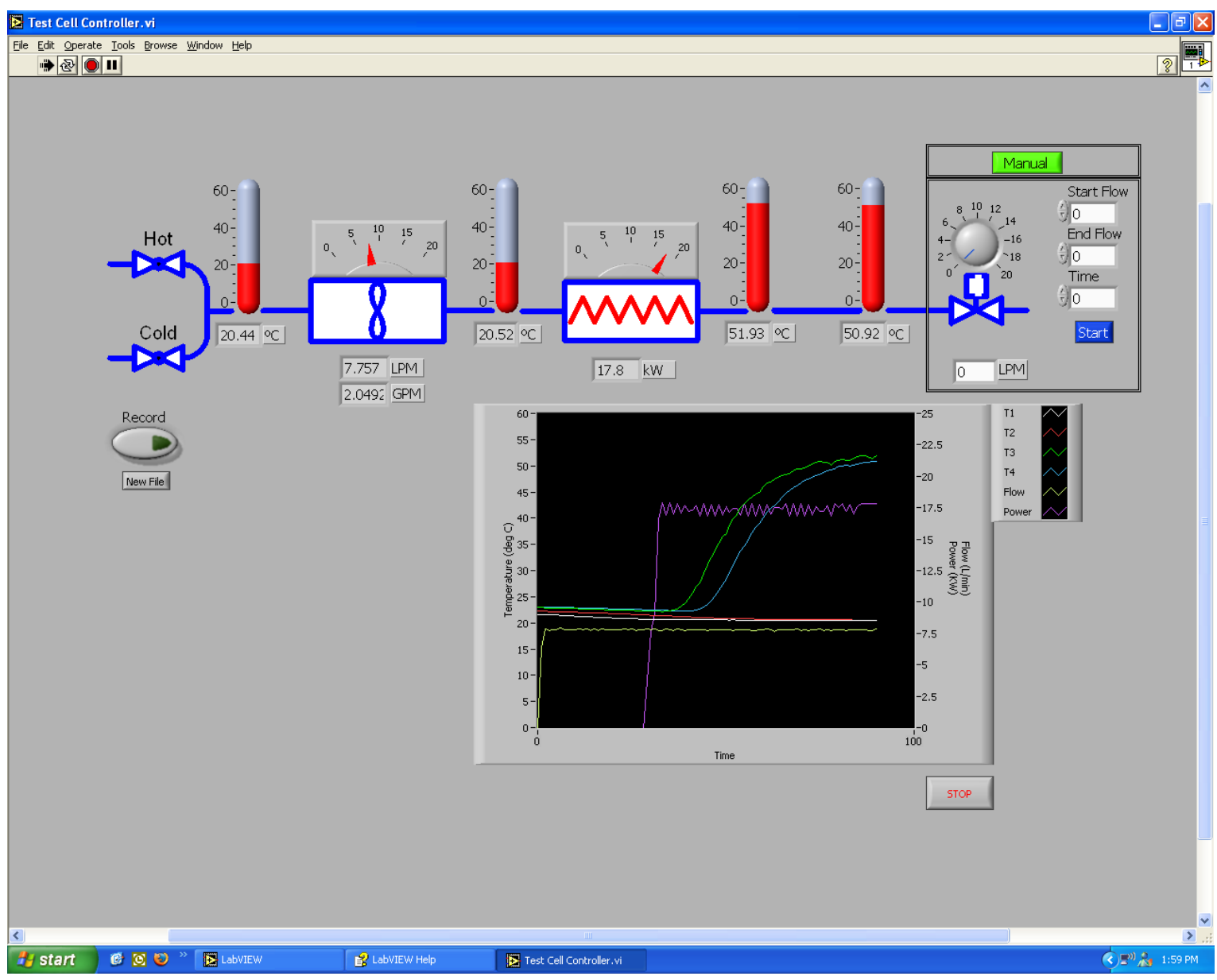

Figure 3: LabVIEW Data Acquisition Interface

\subsubsection{Sensors}

Temperature sensors must be chosen carefully because they must be accurate, but also have rapid response (a low thermal time constant), because of the rapidity and importance of temperature changes in TWH testing. 
Thermocouples - Omega TMTSS-020U-6

Stated Accuracy: $\pm 0.6^{\circ} \mathrm{F}$

Measured Repeatability: $\pm 0.1^{\circ} \mathrm{F}$ comparison between 4 thermocouples, $\pm 0.02^{\circ} \mathrm{F}$ self-comparison

Measurement frequency: $4 \mathrm{~Hz}$

A field check of the temperature sensors' accuracy was conducted after they were interfaced with the DAQ. The four thermocouples were immersed in hot water that was continuously stirred. The probes' tips were in close proximity to each other, and were held against the bottom of the stainless steel pot. The four thermocouples were measured sequentially, and a total of 200 readings ( 50 for each thermocouple) were taken at several different temperatures. Figure 4 shows the error of each thermocouple (defined as the deviation of the reading from the thermocouple to the average of the thermocouples) at the temperatures tested.

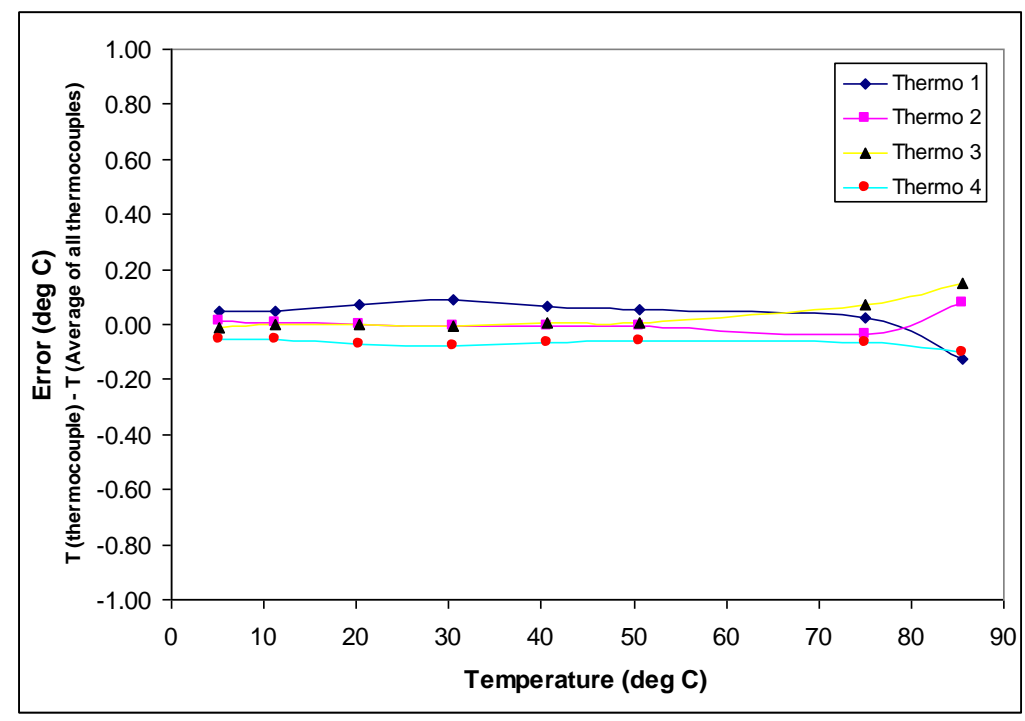

Figure 4: Temperature sensor in-situ calibration

The small magnitude of the errors (less than $0.1^{\circ} \mathrm{C}$ ) at the temperatures encountered in this experiment suggests good confidence in the thermocouple measurements.

A reference to compare the thermocouples to was not readily available. However, the test apparatus needs to measure temperature differences rather than absolute temperature. Therefore, even if the mean temperature measurement was inaccurate, the TWH performance measurement would be accurate.

The transient behavior of the thermocouples was checked to verify an adequately fast response. A thermocouple at thermal equilibrium with the surrounding air was quickly immersed in hot water. This was repeated several times. The results are shown in Figure 3. The three lines are from different tests. The change in temperature - over $50^{\circ} \mathrm{C}$ - occurs entirely within a 0.2 second period, and all significant 
change is within a 0.1 second period. (The immersion time is not at $t=0$; it is unknown and must be inferred from each of the measurements.)

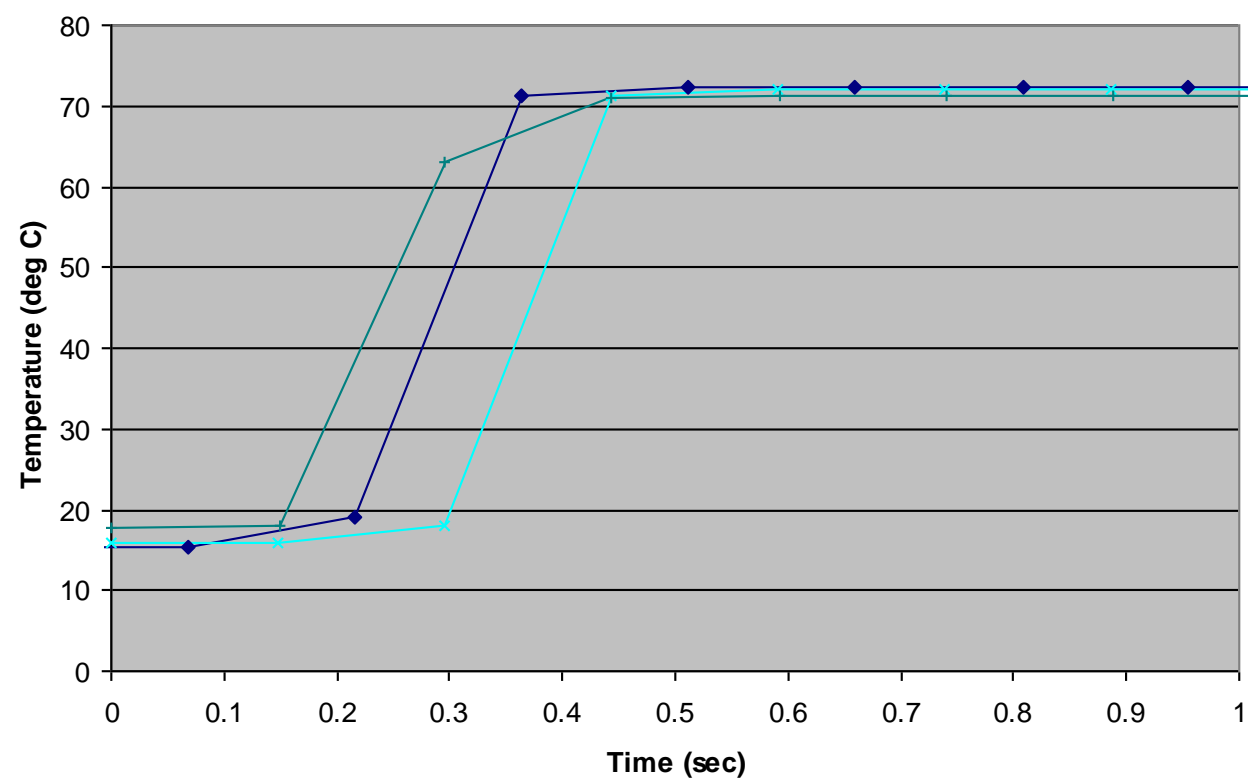

Figure 5: Thermocouple transient response tests

The response shown is adequately rapid to accurately capture the water temperature fluctuations.

Flow Sensor - Appleton GR-EFHC Series

Stated Accuracy: $\pm 0.5 \%$

Stated Repeatability: $\pm 0.02 \%$

Measurement frequency: $20 \mathrm{~Hz}$ (with accumulation time-averaging)

The flow sensor was tested in-situ. The totalized flow read by the flow meter was multiplied by nominal density and compared to the mass of water collected during the test. This test was repeated at various flow rates, concentrating on the flow rates outside of the linear range of the turbine meter.

The scale that weighed the water had a resolution of $0.05 \mathrm{~kg}$ and an accuracy of $\pm 0.11 \mathrm{~kg}$ at our $15 \mathrm{~kg}$ sample size, i.e. about $0.7 \%$. Figure 6 shows the results of the test.

\section{Power Sensor - Omega OM10 Watt Meter}

The power sensor is not required for testing in general. In the current project it was required for development and for diagnosis.

Specified Accuracy: $\pm 0.2 \%$

Measurement frequency: $20 \mathrm{~Hz}$ (with accumulation time-averaging)

The field accuracy of the watt meter was not checked. None of the reported results required a high level of power accuracy. 


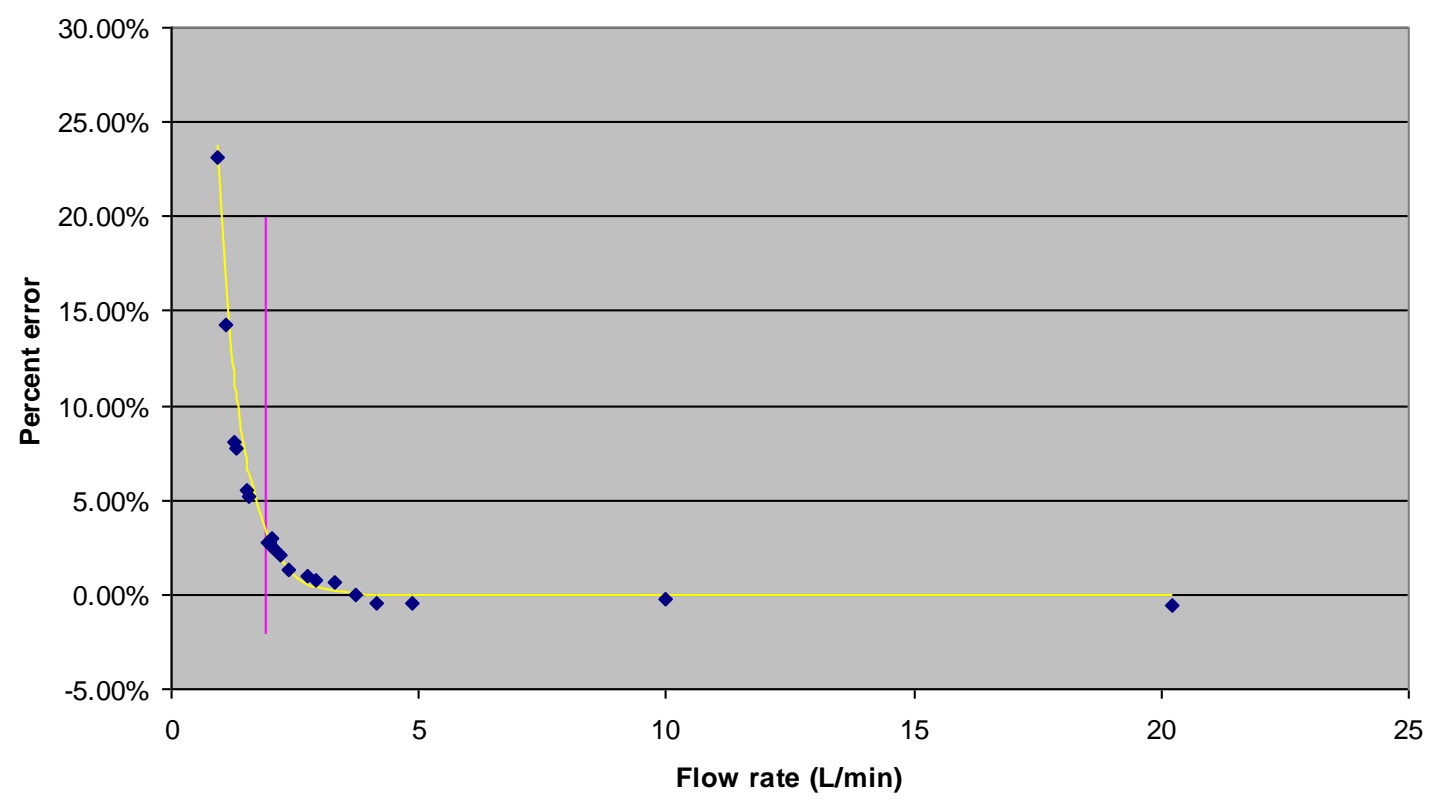

Figure 6: Flow sensor accuracy test

The plotted data are the measured error, defined as the variation between the measured aggregate of the flow through the turbine meter, and the sample in the bucket. The vertical line indicates $1.89 \mathrm{~L} / \mathrm{min}$ (0.5 GPM), which is the typical minimum flow rate for heating in TWH.

The clear repeatable pattern that emerges in the low flow range indicates a bias error that can be corrected for. Therefore we conducted a regression analysis of the data using an exponential fit curve (this curve is suggested by the physical phenomenon and appears to fit well). In the range of our testing ( $0.5 \mathrm{gpm}$ and above) the maximum deviation recorded between the measured data and the correction curve is less than $0.5 \%$.

These data show that the flow sensor that was used is certainly adequate throughout the range of our tests.

\subsection{Testing Heaters}

Heaters from three manufacturers were purchased and tested. These heaters each had a capacity in the range of $18 \mathrm{~kW}$. Two are manufactured in the USA, and one in Europe.

There were several purposes for testing these heaters.

1. To illustrate the kinds of control problems that a control performance test needs to sense and characterize 
2. To provide the first quantitative data that support the anecdotal evidence that TWH control poorly

3. To understand the control approaches used by different manufacturers (by inverse modeling). The TWH industry is very non-standardized with respect to control approaches.

4. To see what level of performance had to be exceeded by the controller developed in this project.

These heaters were tested with an exhaustive set of tests, 60 in total, to ensure that the tests would capture all of the different possibilities for control performance problems. Data are collected for 60 seconds for each test, giving roughly 2900 data per test, or 14,000 data per heater. Experimentation has shown that the majority of disturbances have settled within a 60 second time period.

\subsubsection{Test Results}

For each test these data are plotted, as shown in Figure 7. This figure depicts the response to a flow rate step from $2.8 \mathrm{~L} / \mathrm{min}$ to $7.6 \mathrm{~L} / \mathrm{min}$. This heater begins to ramp up its power (red line) for about 8 seconds, then continues this ramp up far more slowly for the duration of the test, as the outlet temperature continues to stay below setpoint. This behavior is a classic response from a PID (proportional-integral-derivative) controller. The outlet temperature (green) dips from $50^{\circ} \mathrm{C}$ (the steadystate temperature prior to the flow rate change) down to a minimum of $36^{\circ} \mathrm{C}$ at $t=7 \mathrm{~seconds}$, then slowly rebounds, but experiences a constant offset error of about $4^{\circ} \mathrm{C}$. This plot shows temperature control that would cause a severe discomfort event to a user in a shower.

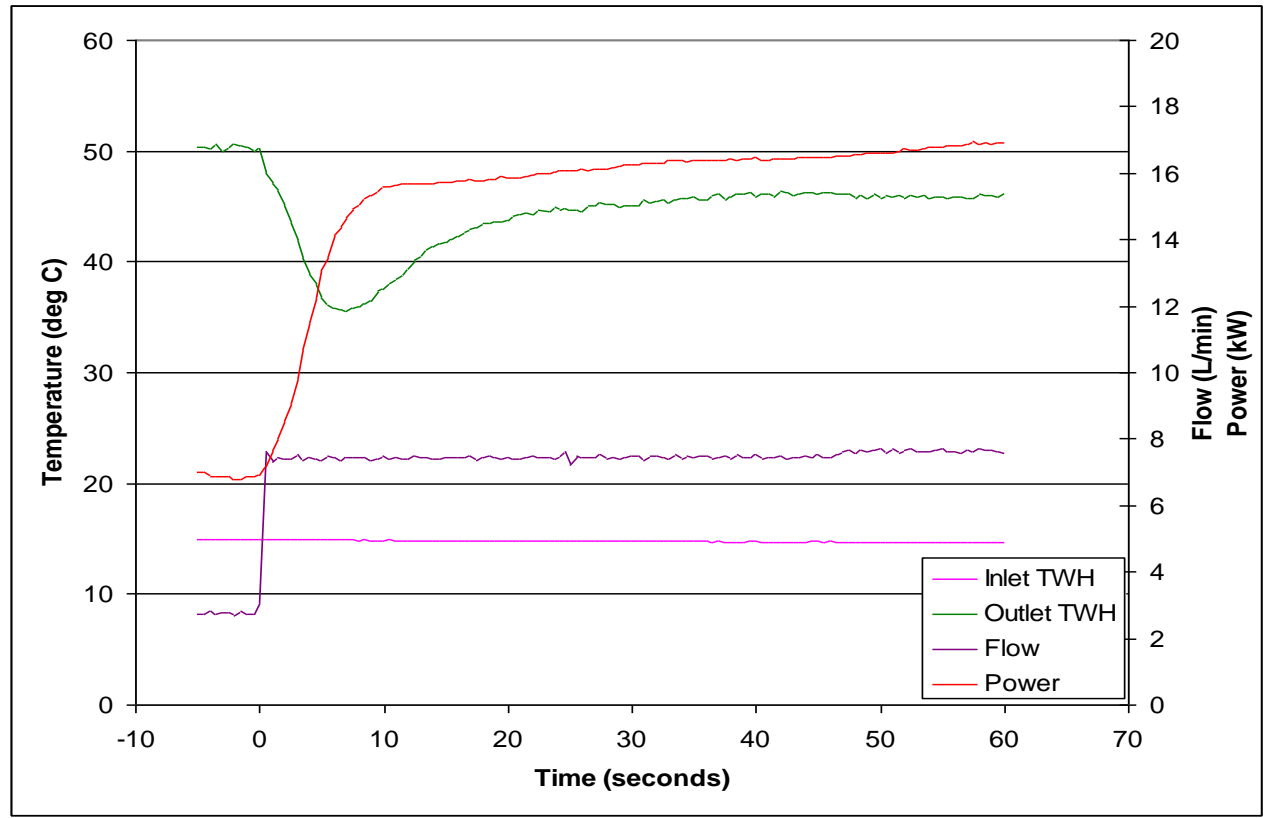

Figure 7: Temperature response of a TWH to a step change in flow rate 
Another example, from a different heater is shown below in Figure 8. This controller appears to use PIDbased control that has been modified with a complex algorithm that causes the power to fluctuate rapidly. The control here is better than for the heater in Figure 7, but a significant constant-offset error still results - about $3^{\circ} \mathrm{C}$. Furthermore, the rapid power fluctuations may cause shorter heater element life, and "flicker factor", a situation in which lights in the home flicker because of the voltage fluctuations associated with varying such a large load so rapidly.

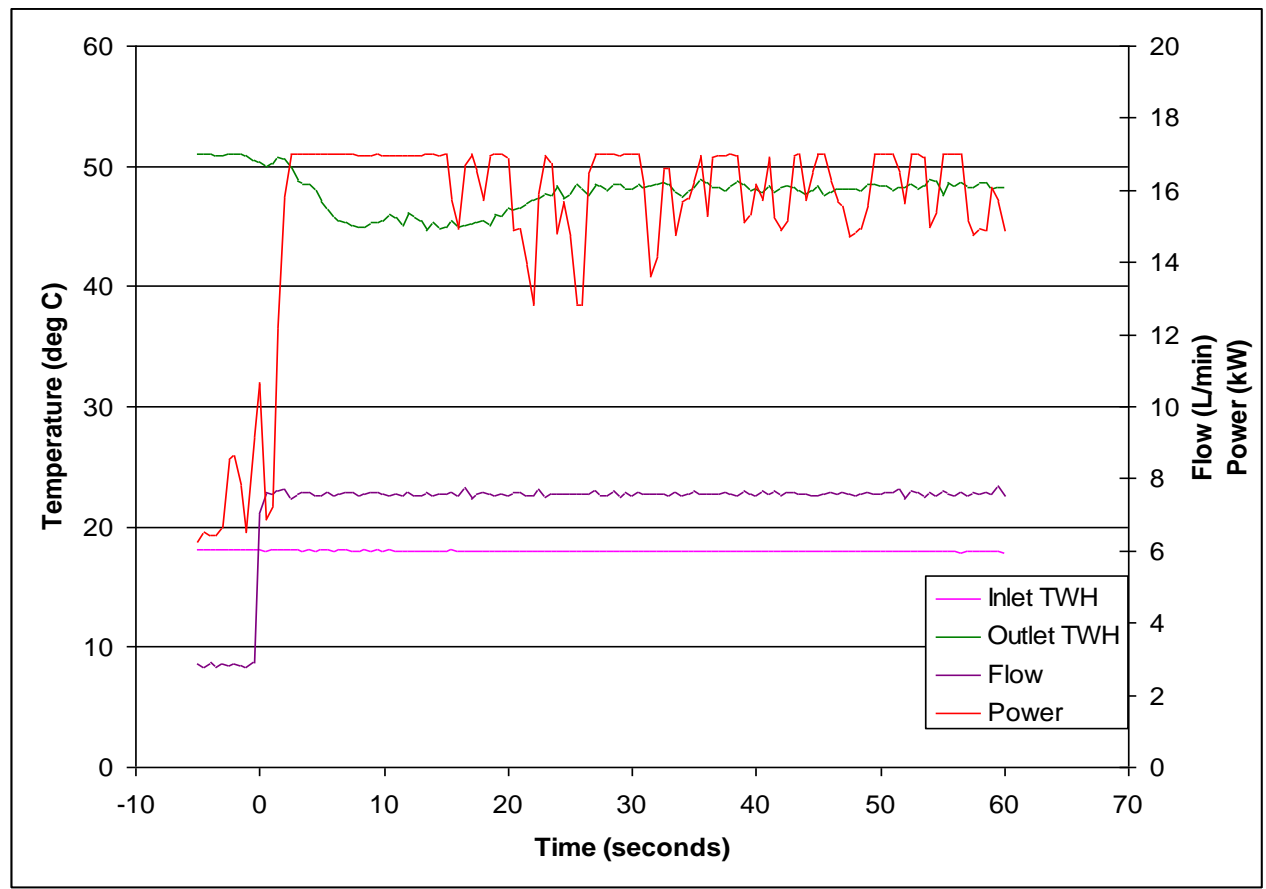

Figure 8: Temperature response of another TWH to a step change in flow rate

The battery of tests on the three heaters showed control problems in each one; the research team deems the control performance of all three heaters to be unacceptable. The maximum deviation (undershoot or overshoot) in each of the heaters:

TWH 1: $11^{\circ} \mathrm{C}\left(20^{\circ} \mathrm{F}\right)$

TWH 2: $11^{\circ} \mathrm{C}\left(20^{\circ} \mathrm{F}\right)$

TWH 3: $26^{\circ} \mathrm{C}\left(47^{\circ} \mathrm{F}\right)$

The deviations shown above are not brief; they occur over a sufficient time period that the damping effect of the distribution piping is not likely to ameliorate the problem before the off-temperature water reaches the end user.

The purposes of this testing, described above in section 2.4, were met. A conclusion can be drawn that the current state-of-the-art in TWH temperature control performance is very poor. Based on an analysis 
of the results of this testing a revised test method that requires only 11 tests was developed, as shown in Table 3 on page 8.

\subsubsection{Special Case: Cold start tests}

Cold start tests are ones in which the flow rate steps up from zero to some value. In all other tests the system has reached a steady state before a test is started, i.e. before a step change is imposed. However, for the cold start tests the entire system would need to reach room temperature, including the water supply lines. Then the water temperature would not be steady as it entered the heater; the volume of water in the supply pipe would provide a plug of room temperature water, which is not normally at the supply water temperature.

To overcome this problem cold start cases are conducted with the full flow rate provided before the start of the test, but with no power delivered. At $t=0$ the power is provided to the TWH. This gives an identical result to a perfect step-up in flow with water at constant temperature.

\subsection{Temperature Control Performance Rating}

Due to the difficulty of describing the control performance, a rating system was developed. This system was developed with the intent of accurately matching the comfort requirement of a user in a showerthe most stringent and most important temperature control requirement in a residential setting - while still being simple and concise.

The control performance is rated based on the integral of the square of the error (ISE) over the 60second test period.

$$
I S E=\int_{t=0}^{60} e^{2} d t
$$

The ISE algorithm was selected because it more strongly penalizes larger magnitude errors and minimizes the weighting of smaller errors, which is similar to human perception of water temperature. For example, temperature swings less than $+0.3^{\circ} \mathrm{C}$ or $-0.2^{\circ} \mathrm{C}$ are typically not detected by humans in showers [Herrmann 1994], and therefore should not be penalized significantly.

The ISE calculation can be easily performed numerically in a spreadsheet program. 


\section{Development of an Improved Controller}

The objective for this phase of the project was to use advanced control methodology to develop a controller that gives a TWH better control performance than any currently on the market. Advanced control methodologies include adaptive control, robust control, expert systems, fuzzy logic, artificial neural networks, and model predictive control [Burns 2001].

Model predictive control (MPC) was selected as the appropriate advanced control methodology for the TWH application. It was anticipated that MPC has capabilities that exceed the control needs of the TWH, but since the price of microcontrollers has become so low in recent years, the excess capability has little or no effect on the hardware cost of the controls. By exceeding the control needs, the MPC controller developed in this project was intended to show how good control could be in a practical application; to provide a benchmark against which other control approaches could be compared.

An important factor in selecting a control approach is consideration of unusual applications; in particular, the use of the electric TWH as a booster for alternative heating approaches such as solar or heat pump water heaters. The heater must be able to deliver good control with very low or very high $\Delta \mathrm{T}$ conditions, and possibly rapid changes to inlet temperature. One previously considered advanced control approach for TWH - adaptive fuzzy control - assumed fairly constant inlet water temperature [Haissig \& Woessner 2000].

One important drawback of MPC is that it requires a high level of sophistication and a significant effort to develop. In particular an accurate model of the transient heat transfer must be developed. As with any model, this model must be validated and tuned, if necessary. This means that an accurate measurement device, such as the test system described in section 2.3 , is required. Since the model is used as the basis of the control decisions, any flaw or inaccuracy in the model tends to compound the error in the temperature output.

\subsection{Technical description of development of MPC for a prototype heater}

An $18 \mathrm{~kW}$ prototype heater was selected as the development platform. This is smaller than a typical whole-house heater; the rationale is that after developing MPC control for one heater, modifying it for a different sized heater requires relatively little effort.

The subject TWH has three chambers of $3.2 \mathrm{~cm}$ diameter copper pipe connected in series through headers. Each chamber contains a $6 \mathrm{~kW}$ tubular heater, consisting of a nickel-chromium resistance wire element, surrounded by powdered magnesium oxide insulation, wrapped in an austenitic nickel-based alloy sheath. Each tubular heater is controlled by a TRIAC. The heat input can modulate in a quasi- 
continuous (resolution of $0.8 \%$ of full scale) range from 0 to $18 \mathrm{~kW}$. The total volume of water in the heating chambers and headers is approximately $0.4 \mathrm{~L}$.

Accurate temperature control of TWH is only possible when accounting for the dynamic thermal response of TWH to variations in water flow rate, inlet water temperature, setpoint changes, and other unmeasured disturbances. Conventional feedback control cannot account for the plant dynamics in an anticipatory fashion, nor does it allow for the inclusion of constraints, such as a maximum allowable overshoot error (for scald protection). MPC, however, does have these capabilities.

An overview of the methodology for the MPC controller development follows:

a. TWH Modeling and Validation: A dynamic model of the TWH was created and tuned, accounting for the thermal mass of the components of the tubular heater and heat exchange with the environment, in addition to the thermal energy required to heat the water flow. We developed lumped-parameter thermal models of the TWH and validated these models using experimental data from dynamic tests conducted with the testing system described in section 2.3. Matlab software and its block-based dynamic systems analysis front end, Simulink, were used for modeling.

b. Development of a model predictive controller for tankless water heaters: The Simulink framework is extended with MPC Toolbox - an add-on module specifically for development of model predictive control. Rapid control prototyping is accomplished with a further addon, Real Time Workshop, which automatically generates and compiles source code from the Simulink block models to create real-time software applications on a variety of systems. The complete system allows automatic code generation tailored for a variety of target platforms, a rapid and direct path from system design to implementation and provides a graphical user interface with open architecture. Finally, a hardware target platform, XPC Target, which allows for controller evaluation in the laboratory setting, was used. XPC Target causes a target computer that is connected to the TWH to emulate the performance of any of several available microprocessor families, to test how well a candidate microprocessor will handle the processing requirements of the final application.

c. MPC controller evaluation: The performance of the MPC controller is fine-tuned by minimizing the integral squared error (ISE) discussed in section 2.5 over the 11-test evaluation set shown in Table 3.

\subsubsection{Development of a Thermal Model}

The dynamic thermal model is broken into the two dominant components: the water contained in the heater chamber and the heating element. The thermal mass of the wetted heating chamber 
components does not play a significant role in the dynamic response of the system, and is lumped with the water.

\subsubsection{Heater Chamber Water Content}

For problems involving control system design, a quasi-steady-state approach fails to capture the dynamics that describe the heat transfer problem, so the TWH system must be described dynamically. The simplest approach is the stirred tank methodology which is, in effect, a lumped parameter method for the TWH system. Here, each of the three heater chambers of the prototype TWH is modeled as a series of inter-connected zones such that the thermal properties of each zone can be assumed to be uniform: the outlet water temperature is equal to the zone temperature for each zone. This is an acceptable approximation so long as a sufficient number of zones is used. A third-order approach provides acceptable accuracy for most heat exchanger components. On this basis, we split each of the three heating chambers into three equally-sized series-connected subsystems (with index ' $\mathrm{i}$ ' referring to the inlet condition and index ' $o$ ' to the outlet condition) as shown in Figure 9:

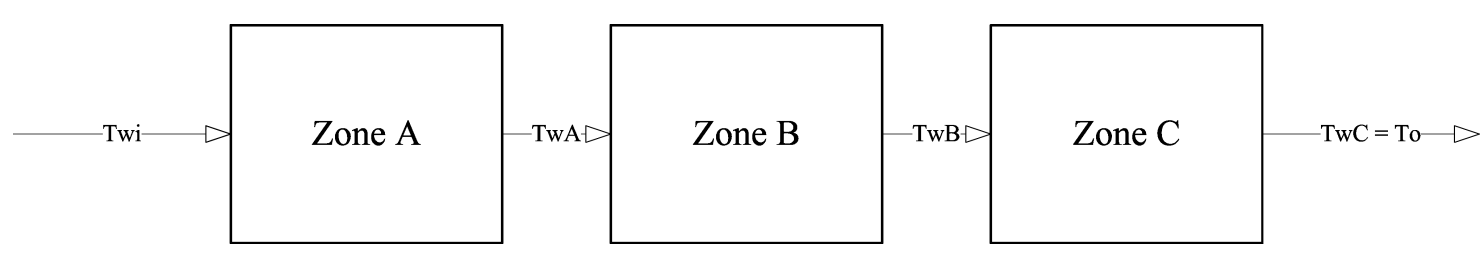

Figure 9: Zoning of a single TWH heating chamber

The water is modeled as flow through an annulus bounded by the cylindrical heating chamber shell on the exterior, and the sheath of the tubular heater on the interior. There are actually several passes of the tubular heater because of its hairpin configuration, but for the purpose of modeling the heat transfer all of the heater elements were assumed to be concentrically located around the center line of the heater chamber, as illustrated in Figure 10.

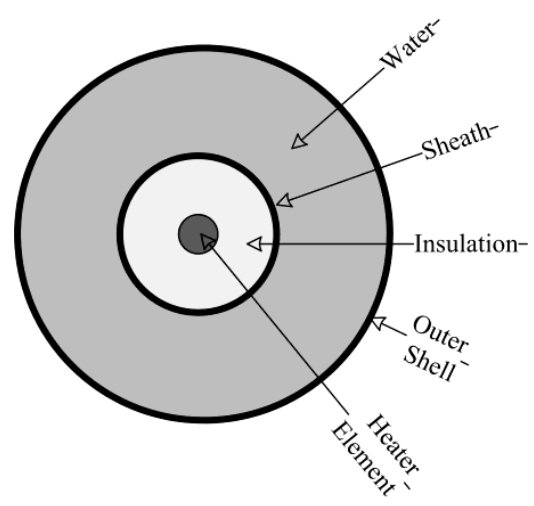

Figure 10: Section through an individual heating chamber 
This assumption allows us to sketch a modified zoning schematic for one chamber of the TWH as shown in Figure 11.

Ambient

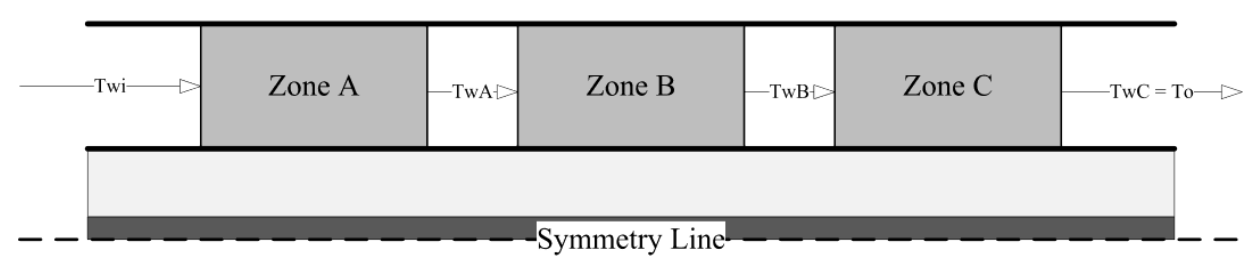

Figure 11: Zoning of heating chamber relative to heater element and ambient

Given the stirred tank philosophy, the mean water temperature is replaced with the zone water temperature. This leads to three energy balances for each chamber. The change of internal energy of each zone is due to a) water flow into and out of the zone, b) convective heat transfer from the surface of the sheath to the water and c) convective heat transfer from the water to the outer heater chamber body. Conduction resistance in the chamber body (the outer shell in Figure 10) is considered negligible, and the chamber body is considered to be adiabatic. The three energy balances are expressed:

$$
\begin{aligned}
& \frac{\mathrm{d} U_{A}}{\mathrm{~d} t}=\rho V_{c h} c_{\mathrm{pw}} \frac{\mathrm{d} T_{\mathrm{wA}}}{\mathrm{d} t}=3 \rho \dot{V}_{c h} c_{\mathrm{pw}}\left(T_{\mathrm{wi}}-T_{\mathrm{wA}}\right)+\frac{T_{\mathrm{sA}}-T_{\mathrm{wA}}}{R_{v s}}+\frac{T_{\mathrm{bA}}-T_{\mathrm{wA}}}{R_{v b}} \\
& \frac{\mathrm{d} U_{B}}{\mathrm{~d} t}=\rho V_{c h} c_{\mathrm{pw}} \frac{\mathrm{d} T_{\mathrm{wB}}}{\mathrm{d} t}=3 \rho \dot{V}_{c h} c_{\mathrm{pw}}\left(T_{\mathrm{wA}}-T_{\mathrm{wB}}\right)+\frac{T_{\mathrm{sB}}-T_{\mathrm{wB}}}{R_{v s}}+\frac{T_{\mathrm{bB}}-T_{\mathrm{wB}}}{R_{v b}} \\
& \frac{\mathrm{d} U_{C}}{\mathrm{~d} t}=\rho V_{c h} c_{\mathrm{pw}} \frac{\mathrm{d} T_{\mathrm{wC}}}{\mathrm{d} t}=3 \rho \dot{V}_{c h} c_{\mathrm{pw}}\left(T_{\mathrm{wB}}-T_{\mathrm{wC}}\right)+\frac{T_{\mathrm{sC}}-T_{\mathrm{wC}}}{R_{v s}}+\frac{T_{\mathrm{bC}}-T_{\mathrm{wC}}}{R_{v b}}
\end{aligned}
$$

or

$$
\begin{aligned}
& \frac{\mathrm{d} T_{\mathrm{wA}}}{\mathrm{d} t}=3 \frac{\dot{V}_{c h}}{V_{c h}}\left(T_{\mathrm{wi}}-T_{\mathrm{wA}}\right)+\frac{T_{\mathrm{sA}}-T_{\mathrm{wA}}}{\rho V_{c h} c_{\mathrm{pw}} R_{v s}}+\frac{T_{\mathrm{bA}}-T_{\mathrm{wA}}}{\rho V_{c h} c_{\mathrm{pw}} R_{v b}} \\
& \frac{\mathrm{d} T_{\mathrm{wB}}}{\mathrm{d} t}=3 \frac{\dot{V}_{c h}}{V_{c h}}\left(T_{\mathrm{wA}}-T_{\mathrm{wB}}\right)+\frac{T_{\mathrm{sB}}-T_{\mathrm{wB}}}{\rho V_{c h} c_{\mathrm{pw}} R_{v s}}+\frac{T_{\mathrm{bB}}-T_{\mathrm{wB}}}{\rho V_{c h} c_{\mathrm{pw}} R_{v b}} \\
& \frac{\mathrm{d} T_{\mathrm{wC}}}{\mathrm{d} t}=3 \frac{\dot{V}_{c h}}{V_{c h}}\left(T_{\mathrm{wB}}-T_{\mathrm{wC}}\right)+\frac{T_{\mathrm{sC}}-T_{\mathrm{wC}}}{\rho V_{c h} c_{\mathrm{pw}} R_{v s}}+\frac{T_{\mathrm{bC}}-T_{\mathrm{wC}}}{\rho V_{c h} c_{\mathrm{pw}} R_{v b}}
\end{aligned}
$$

Here, $U$ is the internal energy $[\mathrm{J}], V_{c h}$ the total chamber volume $\left[\mathrm{m}^{3}\right], c_{p w}$ the specific heat of water $[\mathrm{J} / \mathrm{kgK}], \rho$ the density of water $\left[\mathrm{kg} / \mathrm{m}^{3}\right], \dot{V}$ is the volumetric flow rate through the chamber $\left[\mathrm{m}^{3} / \mathrm{s}\right], R_{v s}$ is the convective heat transfer resistance in $[\mathrm{K} / \mathrm{W}]$ from the surface of the sheath to the water, and $R_{v b}$ is the convective heat transfer resistance in $[\mathrm{K} / \mathrm{W}]$ from the water to the surface of the chamber body. The appearance of overall values for these parameters accounts for the scaling value of 3 in each of the water energy terms in the above. $T_{s A}, T_{s B}, T_{s C}$, are the sheath surface temperatures in zones $A$, $B$, and $C$, 
while $T_{w A}, T_{w B}$, and $T_{w C}$ are the water temperatures in zones $A, B$, and $C . T_{b A}, T_{b B}, T_{b c}$, are the chamber body temperatures in zones $A, B$, and $C$.

\subsubsection{Thermal Model of Heater Elements}

Within each heating chamber zone $(A, B$, or $C)$, modeling is simplified by assuming that the heat transfer is symmetrical about the central heater chamber axis, which leaves a one-dimensional problem (in cylindrical coordinates) to be solved in each heating chamber zone, i.e., heat flow from the tubular heater to the water and from the water to the ambient in a direction perpendicular to the direction of water flow.

One can visualize the problem of transient heat transfer through an opaque multilayer construction element as an equivalent electric RC circuit using a lumped parameter modeling approach:

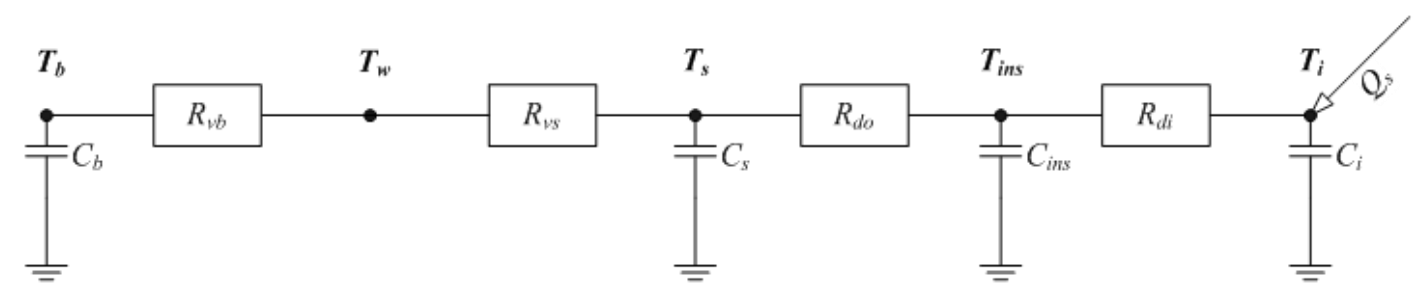

Figure 12: RC network for construction element

This will represent a heater chamber subcomponent of multiple layers using four capacitors, $C_{\mathrm{i}}, C_{i n s}, C_{\mathrm{s}}, C_{b}$, four resistors, $R_{\mathrm{di}}, R_{d o}, R_{\mathrm{vs}}, R_{v b}$, and a heat source $\dot{Q}_{s}[\mathrm{~W}]$ at the core of the tubular heater. The heat source term is multiplied with a heat input efficiency $\eta$ to account for the fact that not all of the heat delivered to the TWH ends up in the water stream; i.e., some it is lost to the environment. $C_{i}$ $[\mathrm{J} / \mathrm{K}]$ is the thermal capacitance of the heater element (wire), $R_{d i}[\mathrm{~K} / \mathrm{W}]$ is the thermal resistance through the annular inner shell of insulation, $C_{i n s}[\mathrm{~J} / \mathrm{K}]$ is the thermal capacity of the insulation, $R_{d o}[\mathrm{~K} / \mathrm{W}]$ the thermal resistance through the annular outer shell of the insulation and the sheath, $C_{s}[\mathrm{~J} / \mathrm{K}]$ is the thermal capacity of the sheath, $R_{v s}[\mathrm{~K} / \mathrm{W}]$ is the convective resistance between the sheath and the water, $R_{v b}[\mathrm{~K} / \mathrm{W}]$ is the convective resistance between the water and the heating chamber body. This model is a fourth-order linear time invariant system with eight parameters (4R4C). As can be seen by the units, all relevant areas must be accounted for.

Based on the total sheath area $A_{s}\left[\mathrm{~m}^{2}\right]$ and the convective heat transfer coefficient $\mathrm{h}_{\mathrm{s}}\left[\mathrm{W} / \mathrm{m}^{2} \mathrm{~K}\right]$, we can determine the convective heat transfer resistance $R_{v s}[\mathrm{~K} / \mathrm{W}]$

$$
R_{v s}=\frac{1}{h_{s} A_{s}}
$$


The conduction heat transfer resistance $R_{d i}$ or $R_{d o}[\mathrm{~K} / \mathrm{W}]$ through the insulation and sheath may be determined from

$$
R_{d}=\frac{1}{2 \pi L \lambda} \ln \frac{r_{o}}{r_{i}}
$$

where $L[\mathrm{~m}]$ is the heating chamber length, $\lambda[\mathrm{W} / \mathrm{mK}]$ the thermal conductivity and $r o[\mathrm{~m}]$ and $r i[\mathrm{~m}]$ the outer and inner radii of layer $j$.

\subsubsection{State Space Formulation}

Now, using notation $\dot{T} \equiv \frac{\mathrm{d} T}{\mathrm{~d} t}$, this thermal network is described by the following energy balances about the surface and inside temperature nodes when substitutions for $C_{\mathrm{i}}, C_{\text {ins }}, C_{\mathrm{s}}, C_{b}$ are made:

$$
\begin{gathered}
C_{\mathrm{b}} \dot{T}_{\mathrm{b}}=\left(T_{\mathrm{w}}-T_{\mathrm{b}}\right) / R_{\mathrm{vb}} \\
C_{\mathrm{s}} \dot{T}_{\mathrm{s}}=\left(T_{\mathrm{w}}-T_{\mathrm{s}}\right) / R_{\mathrm{vs}}+\left(T_{\mathrm{ins}}-T_{\mathrm{s}}\right) / R_{\mathrm{do}} \\
C_{\text {ins }} \dot{T}_{\text {ins }}=\left(T_{\mathrm{s}}-T_{\text {ins }}\right) / R_{\mathrm{do}}+\left(T_{\mathrm{i}}-T_{\mathrm{ins}}\right) / R_{\mathrm{di}} \\
C_{\mathrm{i}} \dot{T}_{\mathrm{i}}=\left(T_{\text {ins }}-T_{\mathrm{i}}\right) / R_{\mathrm{di}}+\eta \dot{Q}_{\mathrm{s}}
\end{gathered}
$$

Rearranging:

$$
\begin{gathered}
\dot{T}_{\mathrm{b}}=\frac{T_{\mathrm{w}}-T_{\mathrm{b}}}{C_{\mathrm{b}} R_{\mathrm{vb}}} \\
\dot{T}_{\mathrm{s}}=\frac{T_{\mathrm{w}}-T_{\mathrm{s}}}{C_{\mathrm{s}} R_{\mathrm{vs}}}+\frac{T_{\text {ins }}-T_{\mathrm{s}}}{C_{\mathrm{s}} R_{\mathrm{do}}} \\
\dot{T}_{\text {ins }}=\frac{T_{\mathrm{s}}-T_{\text {ins }}}{C_{\mathrm{ins}} R_{\mathrm{do}}}+\frac{T_{\mathrm{i}}-T_{\text {ins }}}{C_{\text {ins }} R_{\mathrm{di}}} \\
\dot{T}_{\mathrm{i}}=\frac{T_{\text {ins }}-T_{\mathrm{i}}}{C_{\mathrm{i}} R_{\mathrm{di}}}+\frac{\eta \dot{Q}_{\mathrm{s}}}{C_{\mathrm{i}}}
\end{gathered}
$$

The outputs, $T_{b}, T_{s}, T_{\text {ins }}, T_{i}$, are defined as the state variables; $\dot{T}_{\mathrm{b}}, \dot{T}_{\mathrm{s}}, \dot{T}_{\mathrm{ins}}, \dot{T}_{\mathrm{i}}$ are the time rate changes of the state variables; $T_{\mathrm{w}}, \dot{Q}_{\mathrm{s}}$ are the input variables and $R_{v s}, R_{v b}, R_{d o}, R_{d i}, C_{b}, C_{s}, C_{i n s}, C_{i}, \eta$ are parameters. We can express these equations in matrix-variable or state space notation:

$$
\begin{aligned}
& \dot{\mathbf{x}}=\mathbf{A x}+\mathbf{B u} \\
& \mathbf{y}=\mathbf{C x}+\mathbf{D u}
\end{aligned}
$$

in which $\dot{\mathbf{x}}$ is a vector of state derivatives; $\mathbf{x}$ and $\mathbf{u}$ are vectors of state and input variables; $\mathbf{y}$ is a vector of output variables and A, B,C, D are matrices of parameters. Specifically: 


$$
\begin{aligned}
& {\left[\begin{array}{c}
\dot{T}_{b} \\
\dot{T}_{s} \\
\dot{T}_{i n s} \\
\dot{T}_{i}
\end{array}\right]=\left[\begin{array}{cccc}
-\frac{1}{C_{b} R_{v b}} & 0 & 0 & 0 \\
0 & -\left(\frac{1}{C_{s} R_{v s}}+\frac{1}{C_{s} R_{d o}}\right) & \frac{1}{C_{s} R_{d o}} & 0 \\
0 & \frac{1}{C_{i n s} R_{d o}} & -\left(\frac{1}{C_{i n s} R_{d o}}+\frac{1}{C_{i n s} R_{d i}}\right) & \frac{1}{C_{i n s} R_{d i}} \\
0 & \frac{1}{C_{i} R_{d i}} & -\frac{1}{C_{i} R_{d i}}
\end{array}\right]\left[\begin{array}{c}
T_{b} \\
T_{s} \\
T_{i n s} \\
T_{i}
\end{array}\right]+\left[\begin{array}{cc}
\frac{1}{C_{b} R_{v b}} & 0 \\
\frac{1}{C_{s} R_{v s}} & 0 \\
0 & 0 \\
0 & \frac{\eta}{C_{i}}
\end{array}\right]\left[\begin{array}{c}
T_{w} \\
\dot{Q}_{s}
\end{array}\right]} \\
& {\left[\begin{array}{l}
y_{1} \\
y_{2} \\
y_{3} \\
y_{4}
\end{array}\right]=\left[\begin{array}{llll}
1 & 0 & 0 & 0 \\
0 & 1 & 0 & 0 \\
0 & 0 & 1 & 0 \\
0 & 0 & 0 & 1
\end{array}\right] \times\left[\begin{array}{c}
T_{b} \\
T_{s} \\
T_{i n s} \\
T_{i}
\end{array}\right]+\left[\begin{array}{cc}
0 & 0 \\
0 & 0 \\
0 & 0 \\
0 & 0
\end{array}\right] \times\left[\begin{array}{c}
T_{w} \\
\dot{Q}_{s}
\end{array}\right]}
\end{aligned}
$$

Next, we would prefer to formulate the coupled differential equations for the water content of the heater chamber in state space notation as well. However, the volumetric flow rate that will appear in state matrix $\mathbf{A}$ is variable, and thus we cannot adopt the state space notation. Part of the problem is nonlinear because two variables (flow and a dependent temperature) appear as a product. Therefore we numerically solved the overall TWH model, using an assembly of state space submodels and the numerical integration of differential equations.

\subsubsection{Complete Model of the Tankless Water Heater Assembly}

The complete model is shown below in Figure 13 and Figure 14 as a block model. The inputs are flow rate (Vdot), inlet temperature (Twi) and input power (Qdots). The output is outlet temperature (Two).

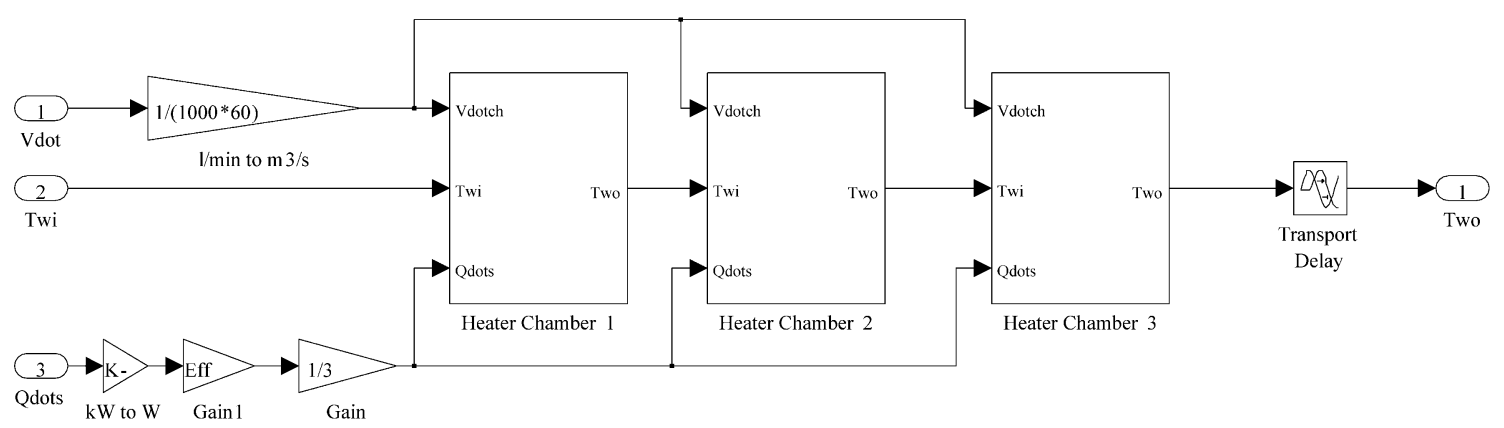

Figure 13: Block model of prototype TWH 


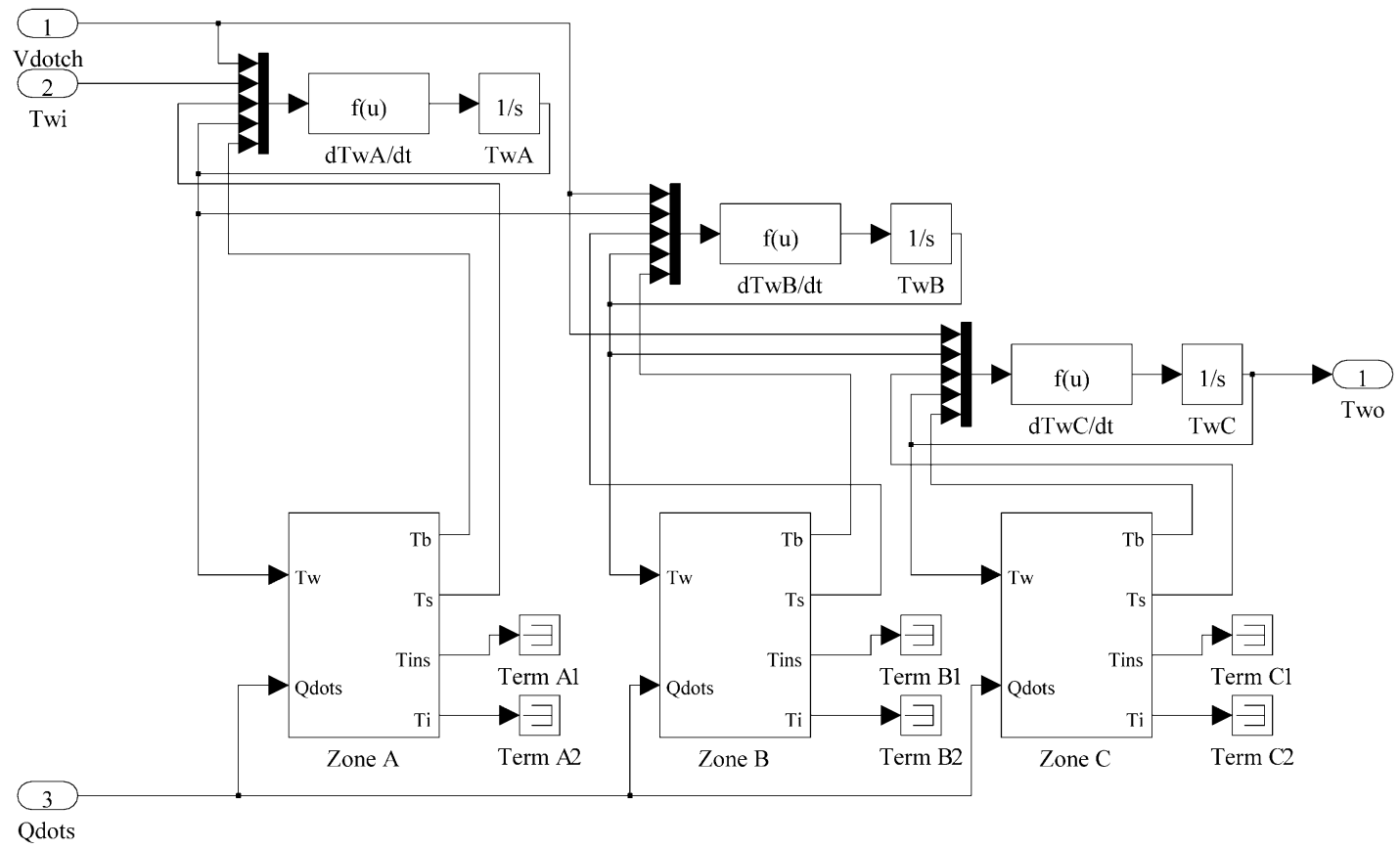

Figure 14: Block model of individual heater chamber

\subsubsection{Model Validation and Parameter Estimation}

To validate the model a test environment was set up in which the behavior of the new dynamic model can be simulated and compared with measured data from the physical prototype. The model validation is conducted in a three-step process consisting of parameter initialization, coarse parameter estimation of highly uncertain parameters, and finally fine parameter estimation of all model parameters. The parameter estimation is conducted within Simulink by calling the TWH model repeatedly, and examining outputs using a nonlinear least squares regression algorithm, until the predicted model response adequately mirrors the measured data.

\subsubsection{Determination of Initial Parameter Values}

Initially, the thermal capacitances $C_{i}, C_{i n s}, C_{s}$, and $C_{b}$ and the conduction resistances $R_{d i}$ and $R_{d o}$ are calculated based on the available measured and manufacturer's data.

\subsubsection{Loosely Bounded Parameter Estimation of Convection Resistances and Volume}

Since the convection resistances $R_{v s}$ and $R_{v b}$ change significantly with flow, a parameter estimation algorithm based on nonlinear least squares minimization was developed to find appropriate parameter value estimates. The TWH water volume $V$, transport delay $t_{d}$, and efficiency $\eta$ were included in the parameter estimation. Reasonable initial values for the parameters to be estimated were derived from 
shorter 1-minute measurements taken on the TWH prototype. These initial values are passed to the system identification routine and solutions are sought within two orders of magnitude of the initial values. Long measurements with a high degree of variance in the driving values were chosen to ensure that a wide range of flow rates would be seen in the system identification process. The top of Figure 15 shows experimental data from the test bed compared to simulated data. The TWH is being controlled by a PID controller and is subjected to flow rate changes, shown in the lower portion of the figure. A long lead-in is followed by a ramp-up, a long settling period, a ramp down, and finally a long settling period. The predicted TWH outlet temperature (gray dashed line) matches the measured value (black line) already within a very narrow band of about 0.1 Kelvin.
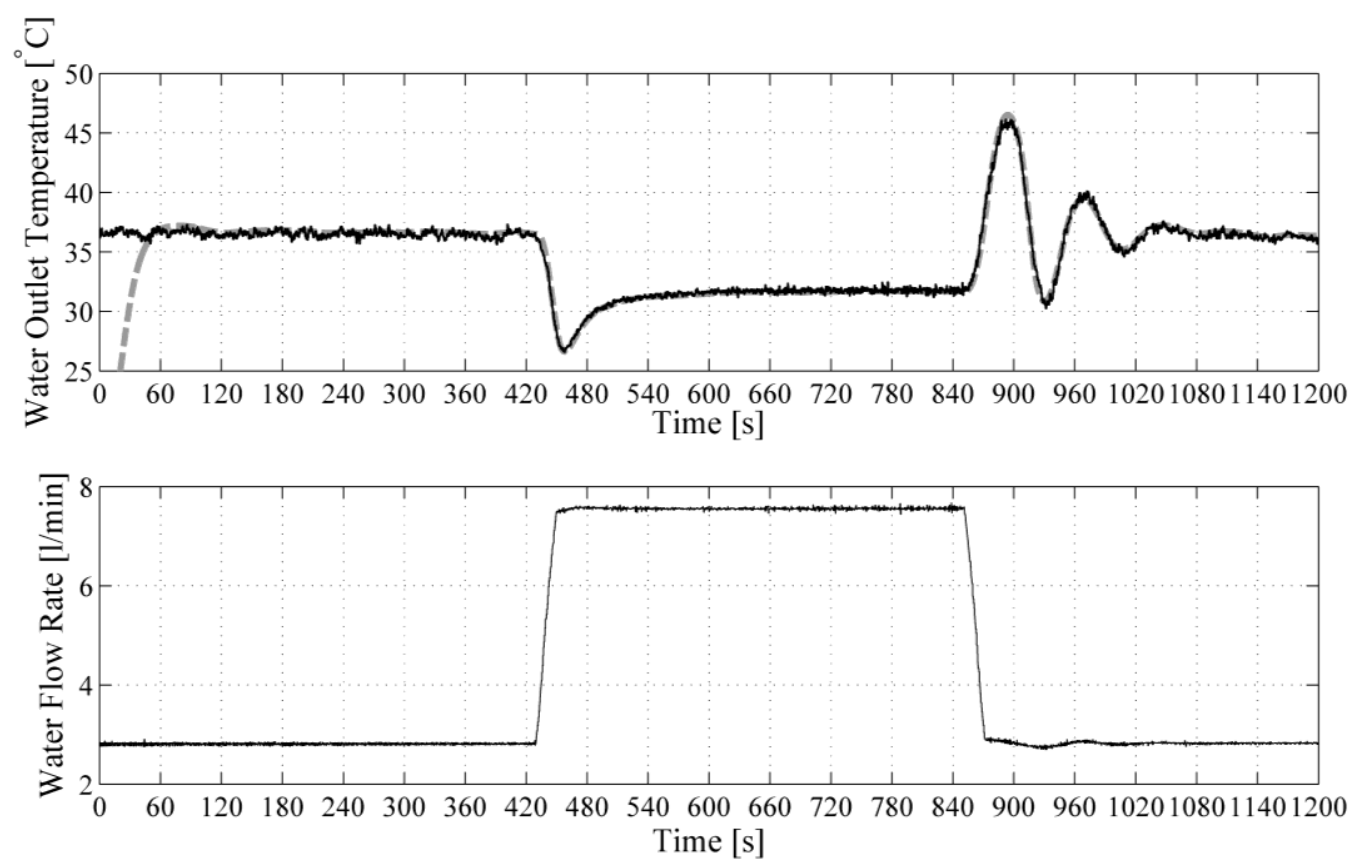

Figure 15: Initial parameter estimation result for training data set

This model also generalizes quite well to changes in inlet temperature, as can be seen in Figure 16. A long lead-in is followed by inlet temperature steps-up and a step-down. Again, the model accuracy is so high that it is difficult to distinguish between the predicted response and the measured response. This figure also shows the classical oscillations of an unstable feedback controller. 


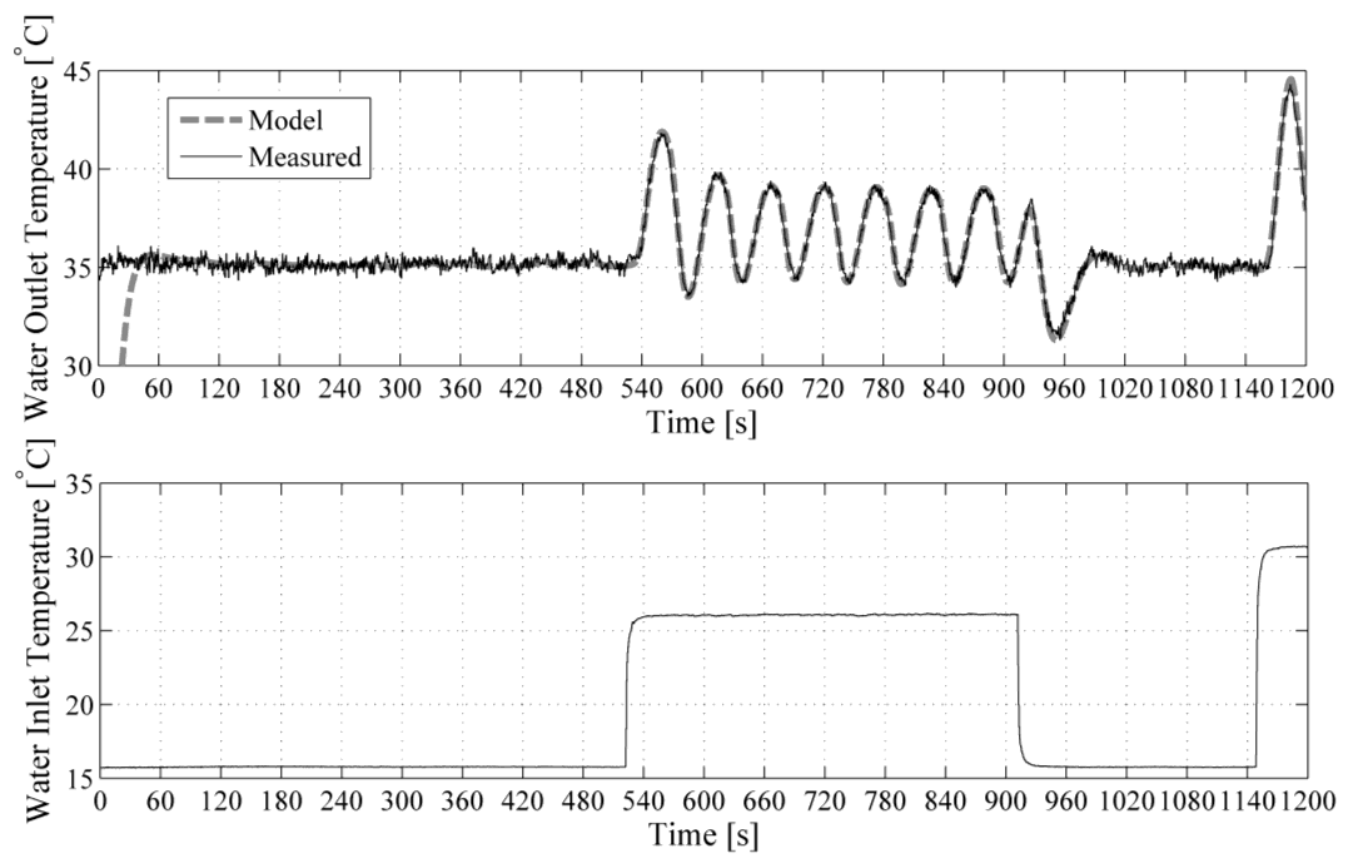

Figure 16: Initial estimated model response and measured result of inlet temperature fluctuation

\subsubsection{Tightly Bounded Parameter Estimation of All Model Parameters}

The five estimated parameters $R_{v s}, R_{v b}, V_{c h}$ transport delay $t_{d}$, and heat input efficiency $\eta$ are now taken as initial guesses for the next step. The parameter estimation process is finalized by including all eleven model parameters ( 4 capacitances, 4 resistances, 1 chamber volume, 1 transport delay, and 1 heat input efficiency) and allowing a refined system identification process to search in a narrow range of $20 \%$ around the six initial $\mathrm{R}$ and $\mathrm{C}$ values as well as the five remaining parameter values identified in the previous parameter estimation step. The final parameter values are within $-18 \%$ and $+10 \%$ of the initial values, with the objective function value decreasing by $4.6 \%$. Obviously, the second estimation step achieved only minor improvements. Visual inspection confirms that only slight improvements in model match could be attained by tuning all nine model parameters around their calculated and initially estimated values.

\subsubsection{Model Reduction}

The linearized models are saved as state-space models with three inputs, one output and 45 states, as there are three chambers each having 15 states (three slices per chamber with 5 integrators associated with 5 temperatures). It is likely that not all of these states are essential, so model reduction could allow for efficient hardware implementation. The given in this report use the full model order, but an analysis showed to what degree model reduction could be employed so that constrained memory and computational performance of embedded controllers would not pose a problem. 
In order to determine the relative amount of energy per state, a Hankel singular value decomposition of the high-flow model revealed that only the first six of the 45 states significantly contribute to the input/output behavior of the TWH, as can be seen in Figure 17. Consequently, a sixth-order approximation is created in which only the first six states are retained using a reduced-order approximation of the linear time invariant (LTI) system.

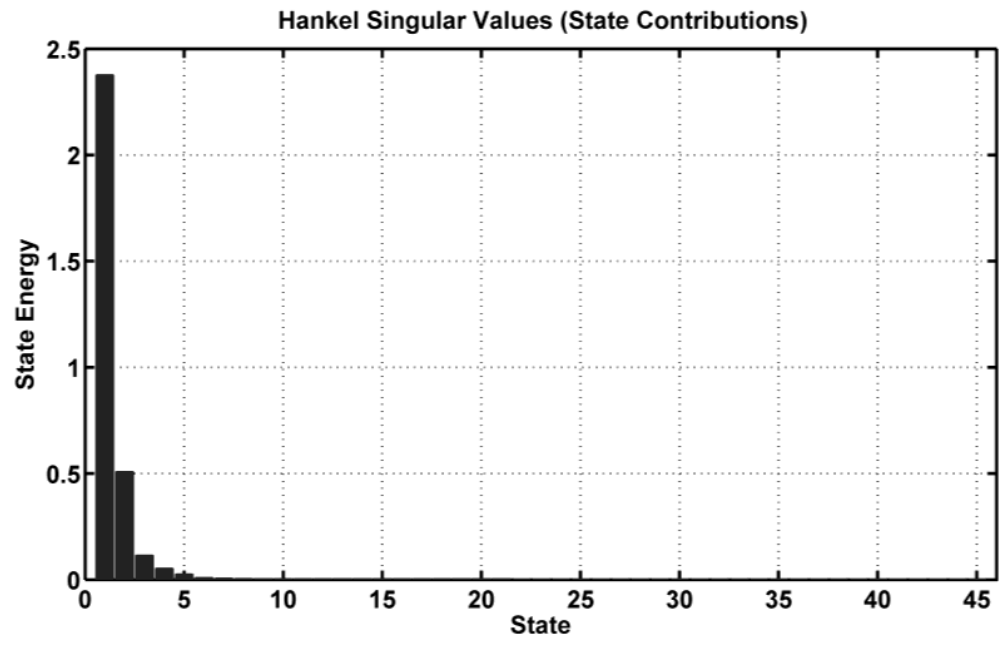

Figure 17: Hankel singular value decomposition showing relative energy per state

To assess the error introduced through the model reduction, the Bode diagram in Figure 18 shows the original 45th-order model in solid lines and the reduced 6th-order model in dashed lines. The magnitude portion reveals that the magnitude of both models in all three input variables drops by 40-60 $\mathrm{dB}$ for excitations up $1 \mathrm{~Hz}$, indicating that the tankless water heater is a slow dynamic system. The point at which the reduced-order model deviates from the original model occurs when the magnitude of the full-order model response has become negligible (-50 dB and less). The phase portion of the Bode diagram also shows that both models are basically in phase for the relevant portion of the forcing frequency $(<1 \mathrm{~Hz})$. In summary, a reduced-order model would be perfectly appropriate for use in a MPC-based TWH controller. 


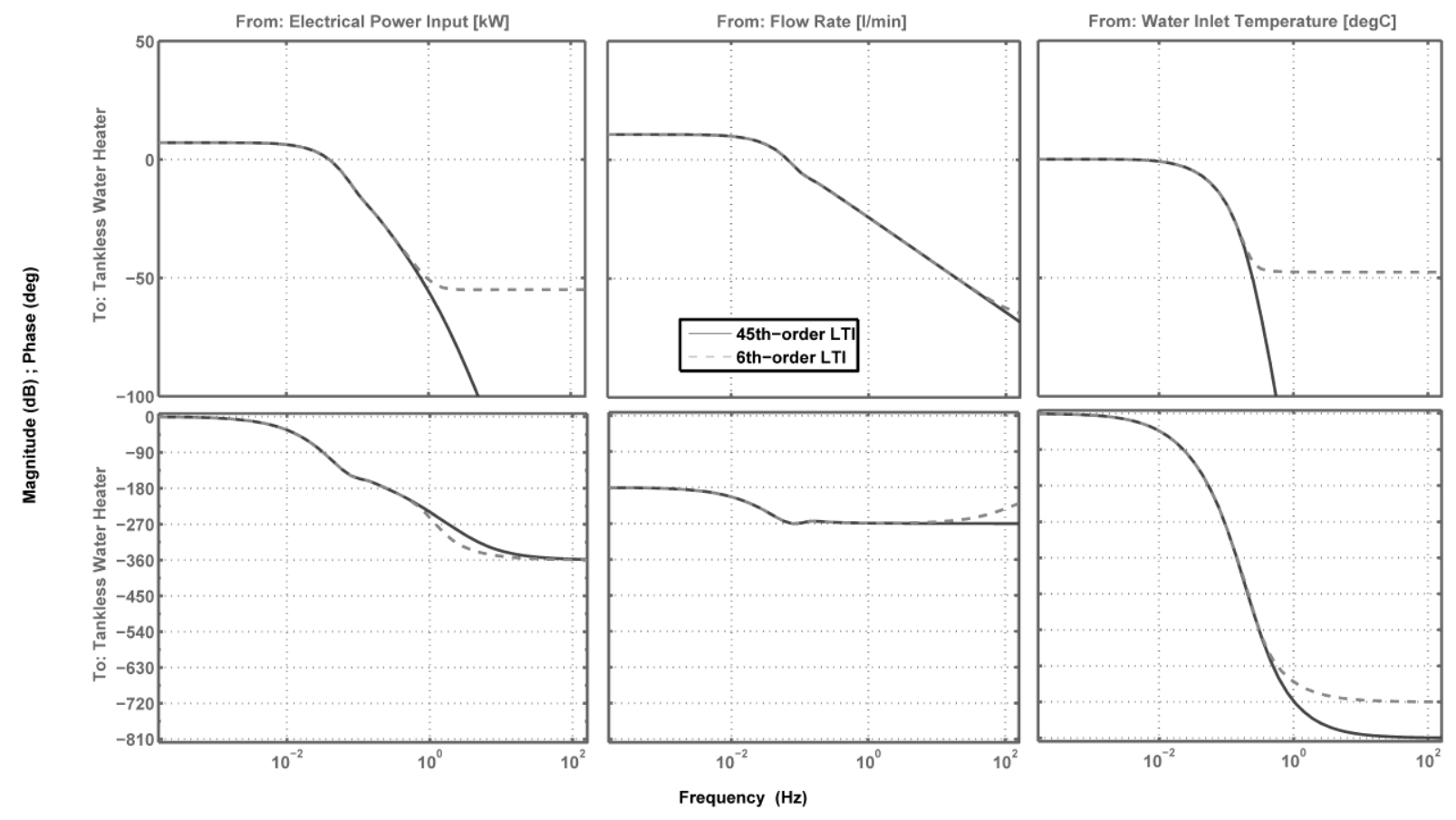

Figure 18: Bode diagram comparing full-order with reduced-order model

With the model completed and validated with experimental results, it was then implemented into a MPC control algorithm.

\subsubsection{Development Environment}

The overall model predictive controller design is supported by a commercial tool chain that enables rapid prototyping of the desired accurate TWH controller. The development environment consists of the following elements employed sequentially:

a) The TWH model development is conducted in Simulink, while the parameter estimation and subsequent validation is achieved with an associated optimization routine in Matlab.

b) Simulink is extended by a toolbox for the design of model predictive controllers (MPC Toolbox 2007). The MPC design entails creating linearized plant models at one or several water flow rates. Because of the nonlinearity caused by the variation in TWH water flow rate, a high-flow and a low-flow plant model are created. The measured flow rate triggers which model the MPC controller uses, in what is called a bumpless transfer design.

c) Once the MPC has been tuned in simulation, rapid control prototyping is accomplished with the help of a further extension for Simulink that automatically generates, packages, 
and compiles source code from the block models to create real-time software applications on a variety of systems (Real-Time Workshop 2007). This extension provides automatic code generation tailored to a variety of target platforms, a rapid and direct path from system design to implementation, and a simple graphical user interface with an open architecture.

d) Finally, a target platform, xPC Target 2007, was used for microcontroller evaluation. The target platform is a solution for prototyping, testing, and deploying real-time systems using standard personal computer (PC) hardware. It is an environment that uses a target PC, separate from a host PC, for running real-time applications. In this environment, one uses a desktop computer as a host $\mathrm{PC}$ with the above mentioned tools to create a model using blocks. After creating the model, one can run simulations in nonreal time. The executable code is downloaded from the host PC to the target PC running the hardware target real-time kernel. After downloading the executable code, one can run and test the target TWH control application in real time in the laboratory setting. The interaction of these tools is shown in Figure 19, below.

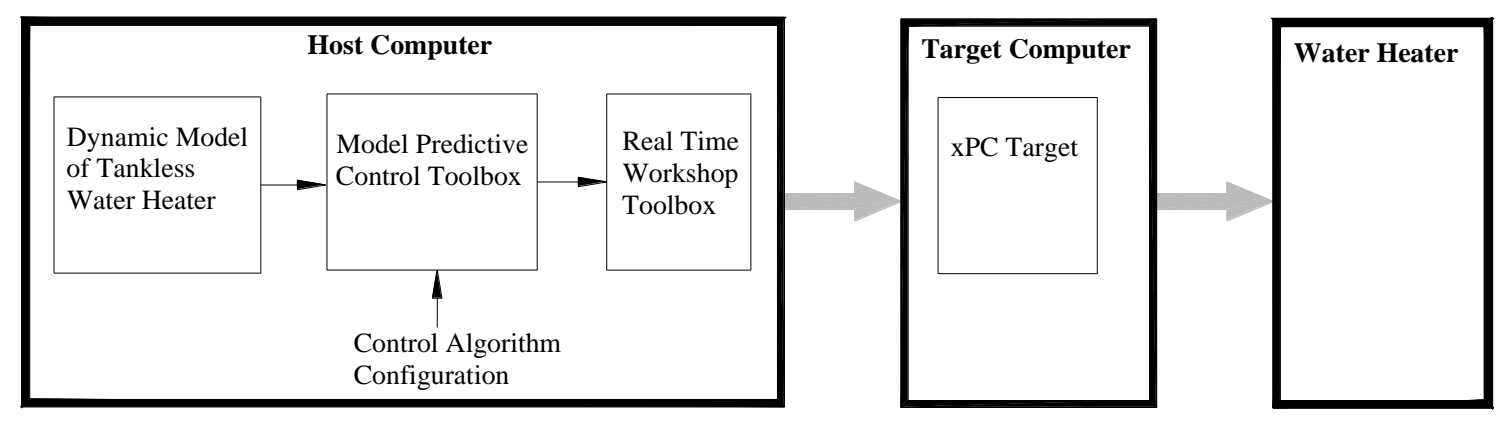

Figure 19: Software and hardware setup for rapid controller prototyping and development

e) The same tool chain could be used to develop production code for embedded microcontrollers selected for the large-scale production of the accurately controlled TWH. Part of the reason this approach was chosen was to provide a streamlined path to production, with rapid modifications for different physical heater configurations.

This development environment has been put assembled to allow for rapid accommodation of changes to hardware and software that are inevitable in a project of this nature. Each element is modular, so that it may be switched out easily. In Figure 20 the system is shown testing a particular control and heat exchanger combination. The heat exchanger is bolted to the water carrying system ( 3 parallel tubes, upper right), but the TRIACs controlling the power to the heating elements are located on a separate panel with the fusing, to the left of the heat exchanger. A different heat exchanger can be substituted very easily. The target computer is black; the host computer is located behind the monitor and keyboard. 


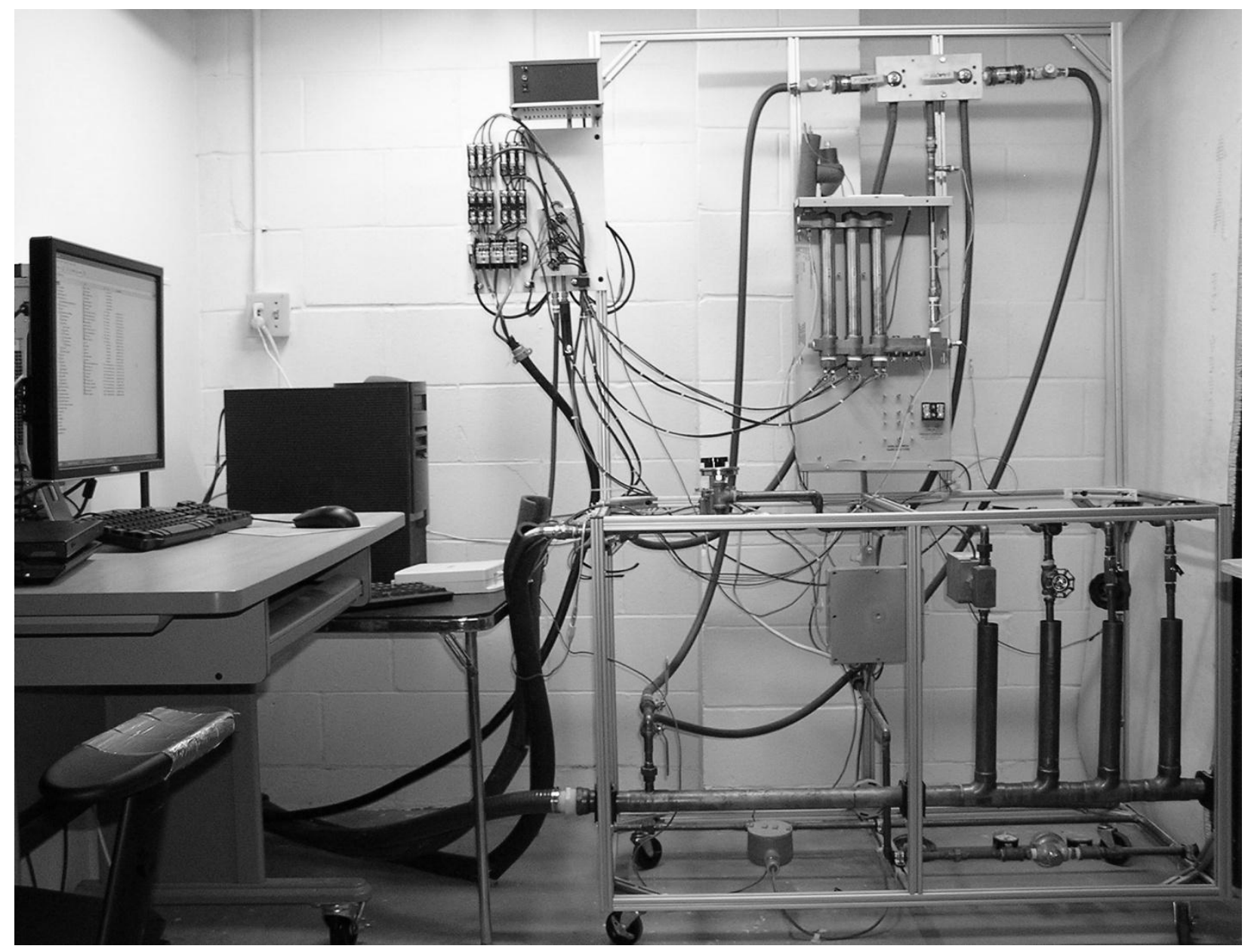

Figure 20: Development platform

\subsubsection{Performance comparison of MPC and existing controller}

The physical TWH was subjected to the 11 test series described in Table 3 while being controlled by the existing PID controller, and while being controlled by the MPC controller. The ISE criterion was evaluated for each of these tests, with the results shown in Table 4 below. Table 4(a) shows the results of flow rate step changes, and Table 4(b) shows the results of inlet water temperature step changes. 
Table 4: ISE results for existing controller and MPC controller

(a)

\begin{tabular}{cccccc}
\hline & \multicolumn{2}{c}{ Flow rate (L/min) } & & \multicolumn{2}{c}{ ISE (K $\left.\mathbf{K}^{\mathbf{2}} \mathbf{s}\right)$} \\
\cline { 2 - 3 } \cline { 5 - 6 } Test \# & Initial & Final & & Existing & MPC \\
\hline 1 & 2 & 8 & & 2271 & 184 \\
2 & 8 & 2 & & 5038 & 2544 \\
3 & 4 & 8 & & 748 & 99 \\
4 & 8 & 4 & & 1229 & 219 \\
5 & 0 & 2 & & 8607 & 7568 \\
6 & 0 & 4 & & 5159 & 4956 \\
7 & 0 & 8 & & 5146 & 3695
\end{tabular}

(b)

\begin{tabular}{cccc}
\hline & $\boldsymbol{T}_{\text {inlet }}$ & \multicolumn{2}{c}{ ISE (K $\mathbf{2}^{\mathbf{s}}$ ) } \\
\cline { 3 - 4 } Test \# & Step (K) & Existing & MPC \\
\hline 8 & +5 & 53 & 25 \\
9 & -5 & 64 & 26 \\
10 & +15 & 510 & 114 \\
11 & -15 & 511 & 150
\end{tabular}

The table shows that the MPC controller substantially reduces the error for this TWH in most of the 11 tests. In other tests the MPC performs only slightly better than the original PID controller, such as Test \# 6. In this test, and Tests 5 and 7 , the flow rate is initially 0 , and the heater is at room temperature. There is a significant time lag before hot water flows from the heater because of the thermal capacitance of the water and heater. Unheated water initially is purged from the heater, and combined with the time lag this gives a large error, regardless of the control technique. This is illustrated in Figure 21, which shows the MPC controller's result to Test 7. (This plot is from a later prototype with a nominal $30 \mathrm{~kW}$ capacity, for which no PID controller ever existed. The results in Table 4 are a comparison of PID and MPC control for the same $18 \mathrm{~kW}$ heater, which gives a more meaningful comparison than for two different heaters. The flow step for Test 6 in the larger heater is scaled accordingly, with a final flow rate of $12 \mathrm{~L} / \mathrm{min}$, instead of $6 \mathrm{~L} / \mathrm{min}$.)

At $t=0$ the controller gives full power (red line) and continues full power until shortly before the temperature (green line) reaches setpoint. This is the best possible action - it brings the temperature up as rapidly as is physically possible. After this it gives a small overshoot then remains at setpoint. However, the ISE is still high because it is heavily dominated by the shaded region on the plot. Thus, the controller is very close to the theoretical optimal performance. 


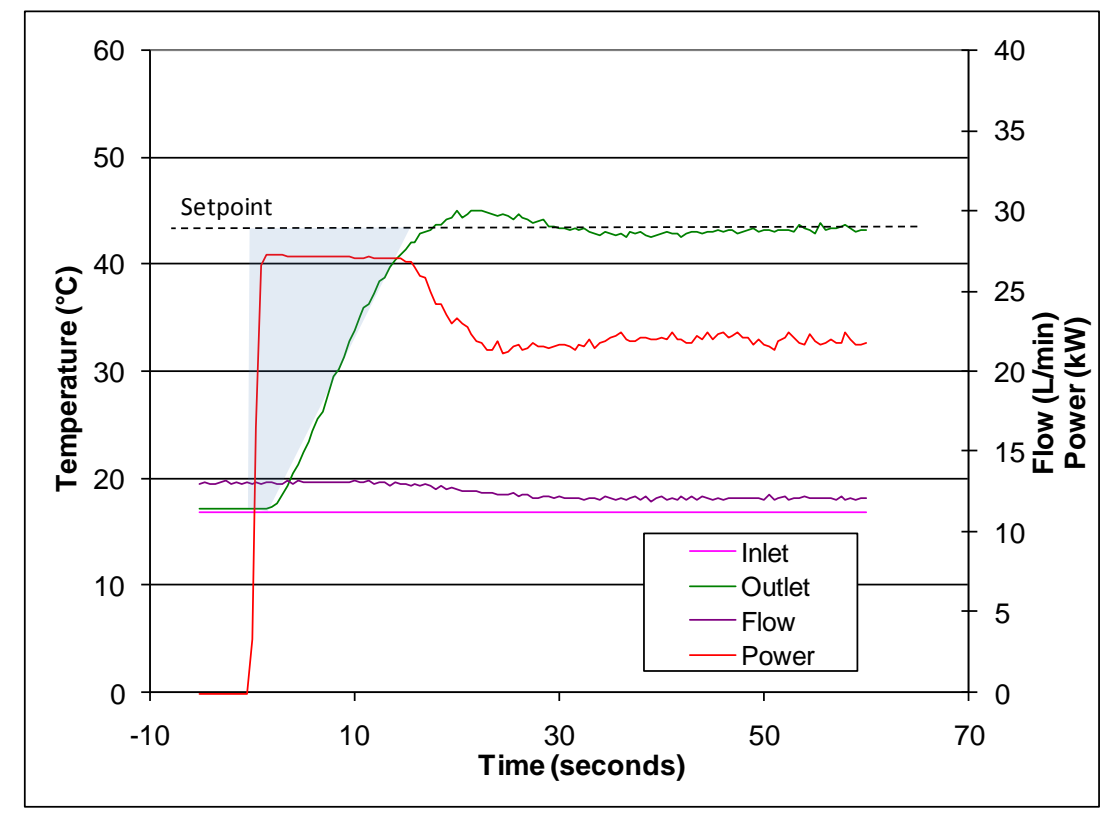

Figure 21: MPC controller performance on test 6 - a cold start with 12 L/min flow

Returning to the comparison of PID and MPC control for the same $18 \mathrm{~kW}$ heater, Table 4 shows that in Test \# 6 the PID performs almost as well as the MPC controller. The reason for this is that this PID controller was tuned at $4 \mathrm{~L} / \mathrm{min}$ - the final flow rate in this test - so it performs quite well at this flow rate. This suggests that a gain-scheduled controller based on a flow rate input (i.e. one that used a different set of PID values for several different flow rates) might perform quite well.

The logged temperatures and power for Test \# 3 and Test \# 4 are shown in Figure 22 . In these tests the TWH is subjected to flow rate steps from 4 to $8 \mathrm{~L} / \mathrm{min}$, and from 8 to $4 \mathrm{~L} / \mathrm{min}$. In Test \# 3 both controllers experience an initial undershoot after $t=0$, where the flow rate step change occurs. This is caused by the same physical constraint described in Figure 21: water cannot be heated instantly. The lower part of the plot shows that the MPC controller immediately gives full power for several seconds again, the best control action available - and this limits the undershoot to its theoretical minimum; about $3^{\circ} \mathrm{C}$. The PID controller slowly ramps up power in response to the error, but has an undershoot of about $8^{\circ} \mathrm{C}$. Furthermore, the PID controller gives a constant offset error of almost $-2^{\circ} \mathrm{C}$. 

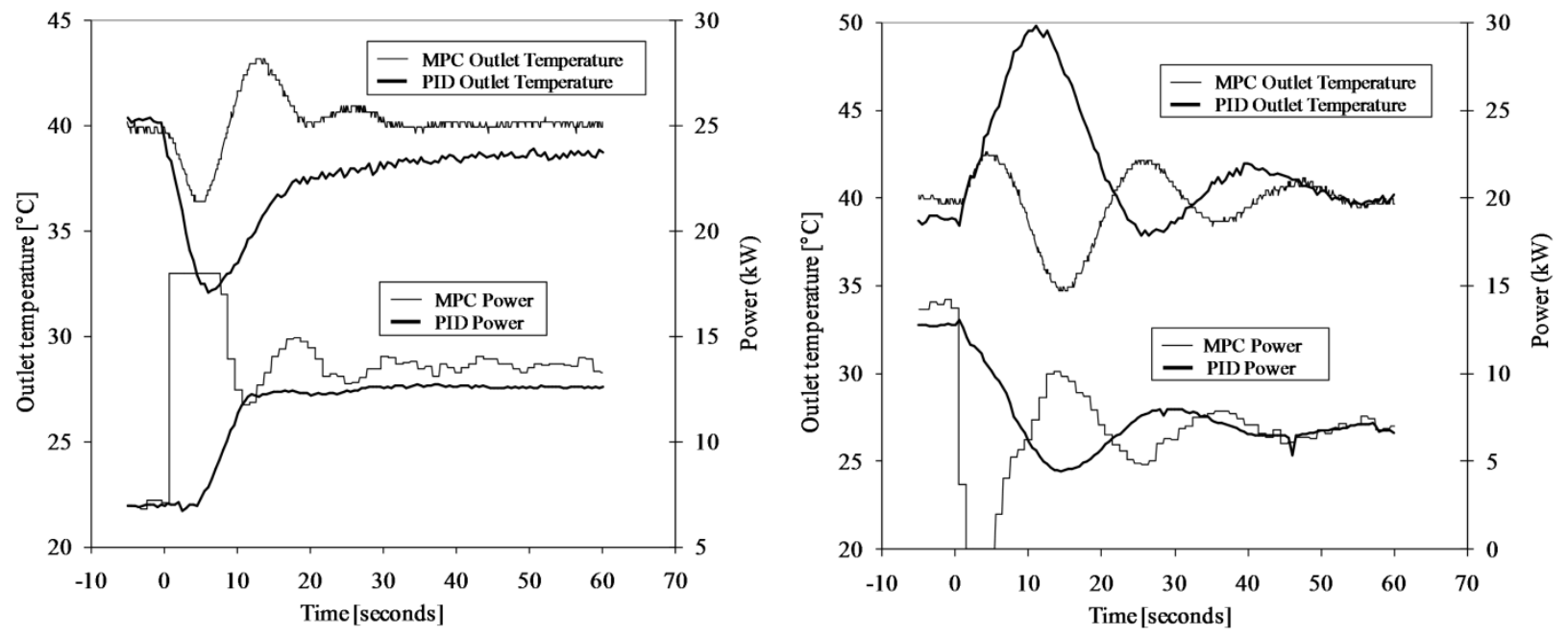

Figure 22: MPC and PID performance comparisons

In Test \# 4, shown on the right side of the figure, the flow rate is stepped from 8 to $4 \mathrm{~L} / \mathrm{min}$. A temperature overshoot is unavoidable because of thermal energy stored in the heater. The MPC controller rapidly cuts power to zero, to minimize the overshoot. The resulting overshoot is less than $3^{\circ} \mathrm{C}$, while the PID controller gives an overshoot of over $10^{\circ} \mathrm{C}$. If this overshoot occurred at the end use (such as a shower supplied by a point-of-use water heater) it would be not only uncomfortable, but dangerous. The seriousness of this overshoot is reflected in the ISE value associated with this test $1229 \mathrm{~K}^{2} / \mathrm{s}$ for the PID controller, compared with $219 \mathrm{~K}^{2} / \mathrm{s}$ for the MPC controller.

The MPC controller in both plots exhibits similar oscillation to what is expected in PID control. There are two possible explanations for this. The first is that the discretization of linearized flow regimes is too coarse (only two are used: low flow and high flow). A second is that there exists a tradeoff between performance and robustness, just as with PID control, and we opted for performance. Additional work would likely improve the performance of the MPC controller, if necessary.

The MPC controller was found to have a lower maximum error and a lower steady state offset for each of the 11 tests.

\subsection{Assessment of alternative control techniques}

The development of the MPC controller described in the previous section can be seen as a benchmark. It is the best control for the TWH application that can be achieved practically. An analysis of the theoretical best control would be of little use; just as a model that has not been validated experimentally is of little use.

Besides the control performance results of the MPC controller, two important insights were gained: 
1) Control for the TWH application is less straightforward than one might assume. Unknown disturbances are more significant and numerous than was anticipated.

2) Development of an MPC controller is far more difficult than was anticipated.

The sponsors of this project have emphasized that a successful outcome is an application that is brought to the marketplace. Implicit in this message is that the results of this project are better if they can be exploited by many (or all) manufacturers of TWH than if only one manufacturer adopts them. Having developed an MPC controller our assessment is that few, if any, TWH manufacturers have the necessary expertise or development capital to develop MPC control for their own heaters, or to contract the work out. Therefore, our next step was to use the MPC result as a benchmark and to assess several simpler control methodologies to compare them with MPC. One approach, described below, turned out to provide excellent control - comparable, and in some cases better than MPC - with a far simpler algorithm. The algorithm is one that most, or all, TWH manufacturers are likely to be able to implement. This work was beyond the scope of the Cooperative Agreement from DOE, but obviously it leverages the overall success of the project vastly.

\subsubsection{Control Approaches}

Seven control approaches were investigated, including the previously discussed MPC and the existing controller. These approaches are

1. The original (off the shelf) controller of Keltech, used in their Acutemp product line. This controller uses PID feedback control tuned with Keltech's own approach.

2. PID feedback control, tuned to the Chien-Hrones-Reswick tuning rules, and tuned at a flow rate at the midpoint of the flow range.

3. PID feedback control as in 2, but gain-scheduled (tuned to a low flow and to a high flow, with a bumpless transfer between the two sets of PID values.

4. PID feedback control, tuned optimally. The optimization minimized the ISE. This controller was also gain-scheduled to two flow rates, as in controller 3.

5. Simple Feed-forward

6. Feedback-Compensated Feed-forward with optimal feedback compensation. In this approach the control action is calculated by combining the feed-forward value with a PID correction value. The feedback compensation was tuned to minimize the ISE.

7. Model Predictive Control

The seven control approaches were tested on the $18 \mathrm{~kW}$ heating unit that has been the subject of most of the work described above. The development system, shown in Figure 19, was used for each 
controller. This allowed each new controller to be programmed into the host computer - often with as little as 4 or 5 lines of code - then downloaded onto the target computer, which behaves as a virtual microcontroller. Without having the development platform in place this assessment would have been more time-consuming: each controller would need to be programmed to a microcontroller, which would then be wired into the controller chassis of the TWH to connect it with the inputs (temperature and flow sensors) and outputs (TRIAC signal).

Each controller was then tested while it controlled the physical heater during the 11-test performance protocol, described in Table 3. The results of this testing are summarized below, in Table 5. The control approaches are numbered as above (in columns) and the tests are numbered as in Table 3 (in rows). The highlighted values are the lowest (best) ISE score for each test.

Table 5: Summary of ISE results for performance test of seven control approaches

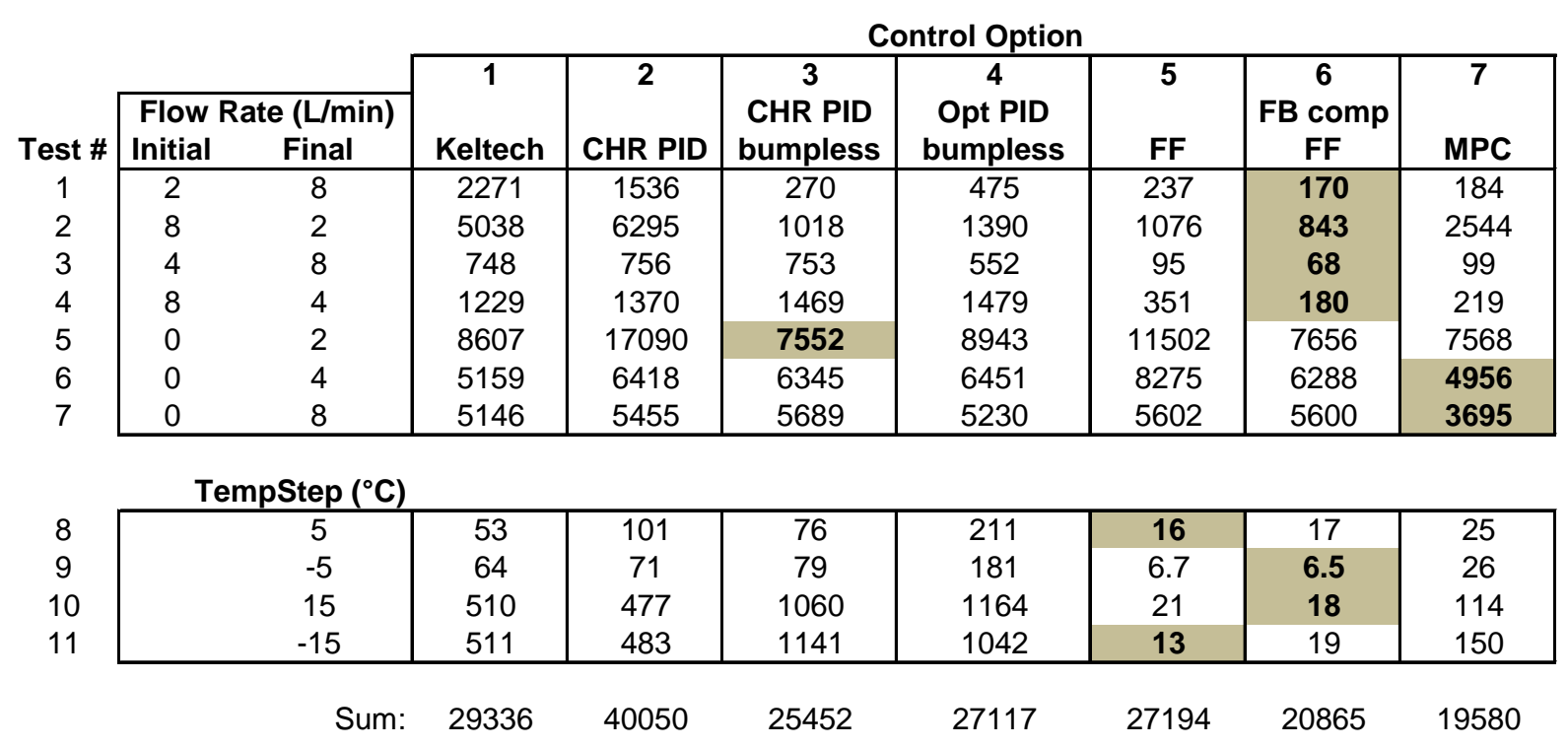

At the bottom of the table the results for each heater are summed for the 11-test set. MPC does have the lowest sum, even though it is the best performer in only two tests. These two tests are flow rate increases from 0 to 4 or 0 to $8 \mathrm{~L} / \mathrm{min}$ - a "cold start" situation, such as turning on a shower while no other hot water devices are being used. In these cases the MPC has sufficient pseudo-intelligence to give full power immediately until it anticipates that an overshoot would occur in the future then backs off the power to avoid this overshoot.

However, for a cold start scenario in a typical house, a quantity of cold water is expected because the pipes must be purged with hot water (and the copper pipe heated) before hot water arrives at the end use. Therefore these tests should be considered less important than others that might involve a user already in a water stream when a flow change happens. 
The conclusion from these results is that the Feedback-Compensated Feed-Forward control is the best approach. This is a surprising result, but it is serendipitous because this approach is so much simpler than MPC.

Some other notes or observations about Table 5:

1. There is a minimum ISE in each case, based on physical constraints (i.e. a zero score is physically impossible). In many cases where there are multiple best performers in the same range, they are all very near this minimum.

2. The Keltech heater performs much better than the CHR-tuned PID. This is essentially the best performance that can possibly be achieved with PID only. (Cases 3 and 4 have scheduling, wherein there are essentially two different PID controllers that are tuned at different flow rates (high and low), with a bumpless transition program between the two. This cannot be implemented by a simple PID controller, and requires a flow sensor.)

3. Step changes in inlet temperature are more easily handled by all controllers because the temperature is sensed upstream of the heat; in the time it takes the water to pass through the heater many control actions can be taken.

\subsubsection{Feedback Compensated Feed-Forward Control}

In light of the superior performance of control approach 6 - Feedback-Compensated Feed-Forward (FBCFF), the specifics of this approach will be explained in greater detail.

FBCFF requires a compensation scheme to be developed. This controller starts with a simple feedforward calculation (the First Law of Thermodynamics: $q=m C_{p} \Delta T$ where $q$ is the rate that heat that must be added, $m$ is the mass flow rate, $C_{p}$ is specific heat, and $\Delta T$ is the difference between inlet and desired water temperatures). To compensate for dynamics (non-steady-state conditions), variations in voltage, and error in the flow sensor, a PID feedback loop is added.

The feed-forward and feedback terms are added to give the total control output. We developed a system for combining these control approaches, although it is likely that this system or other systems exist in the literature. Our system is shown schematically in Figure 23. 


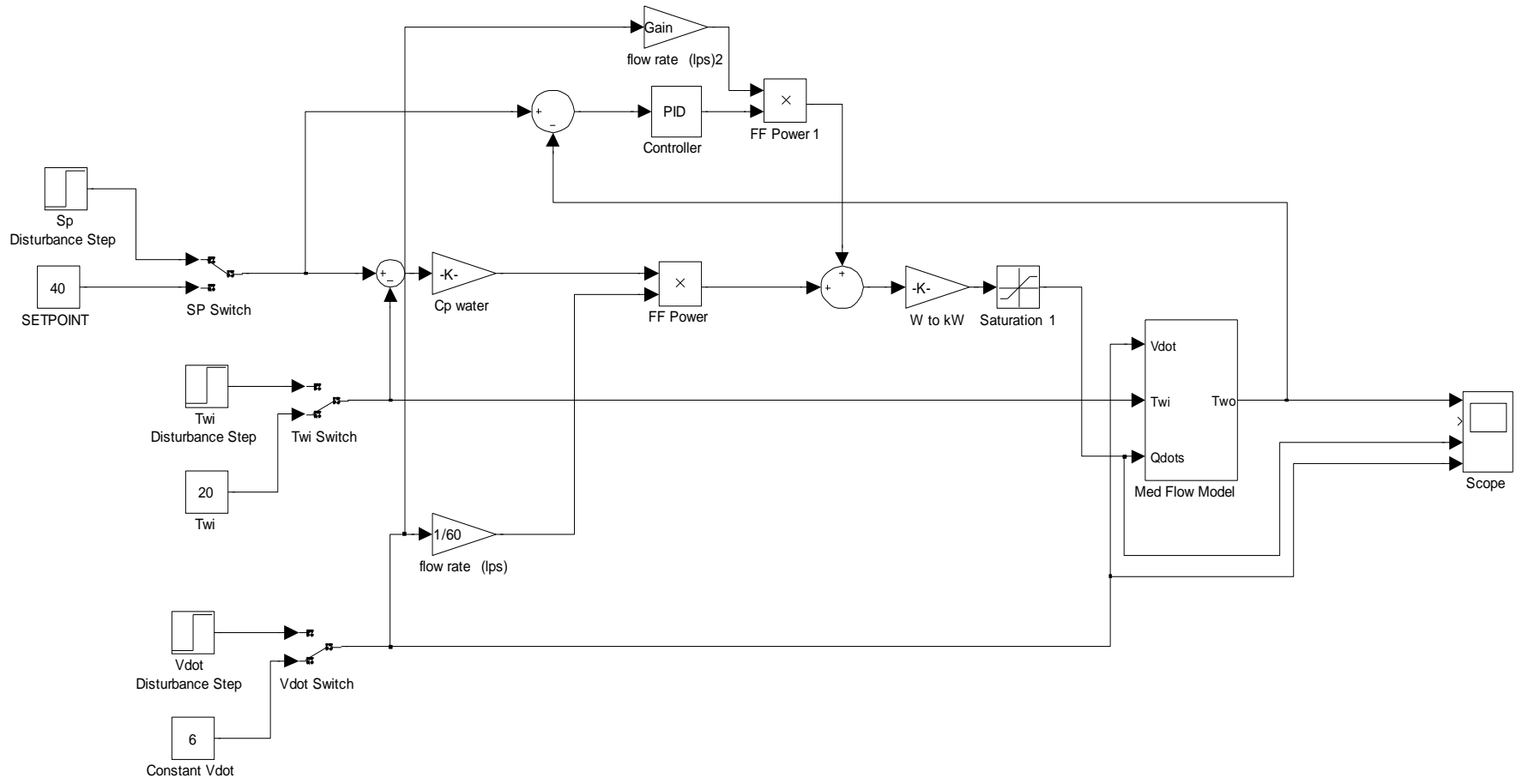

Figure 23: Simulink block diagram of Feedback Compensated Feed Forward Controller

Since the sensitivity of the controller will increase as flow increases, the feedback component is multiplied by the flow rate. We have optimized the tuning parameters of the feedback portion to give the minimum combined ISE value.

\subsection{Hardware Development}

Keltech's existing heater used analog controls, and since it used feedback control only, it had no inlet temperature sensor and no flow rate sensor. Thus, the hardware had to be changed significantly to accommodate the improved control approach.

The final design of the electrical system is shown schematically in Figure 24. 


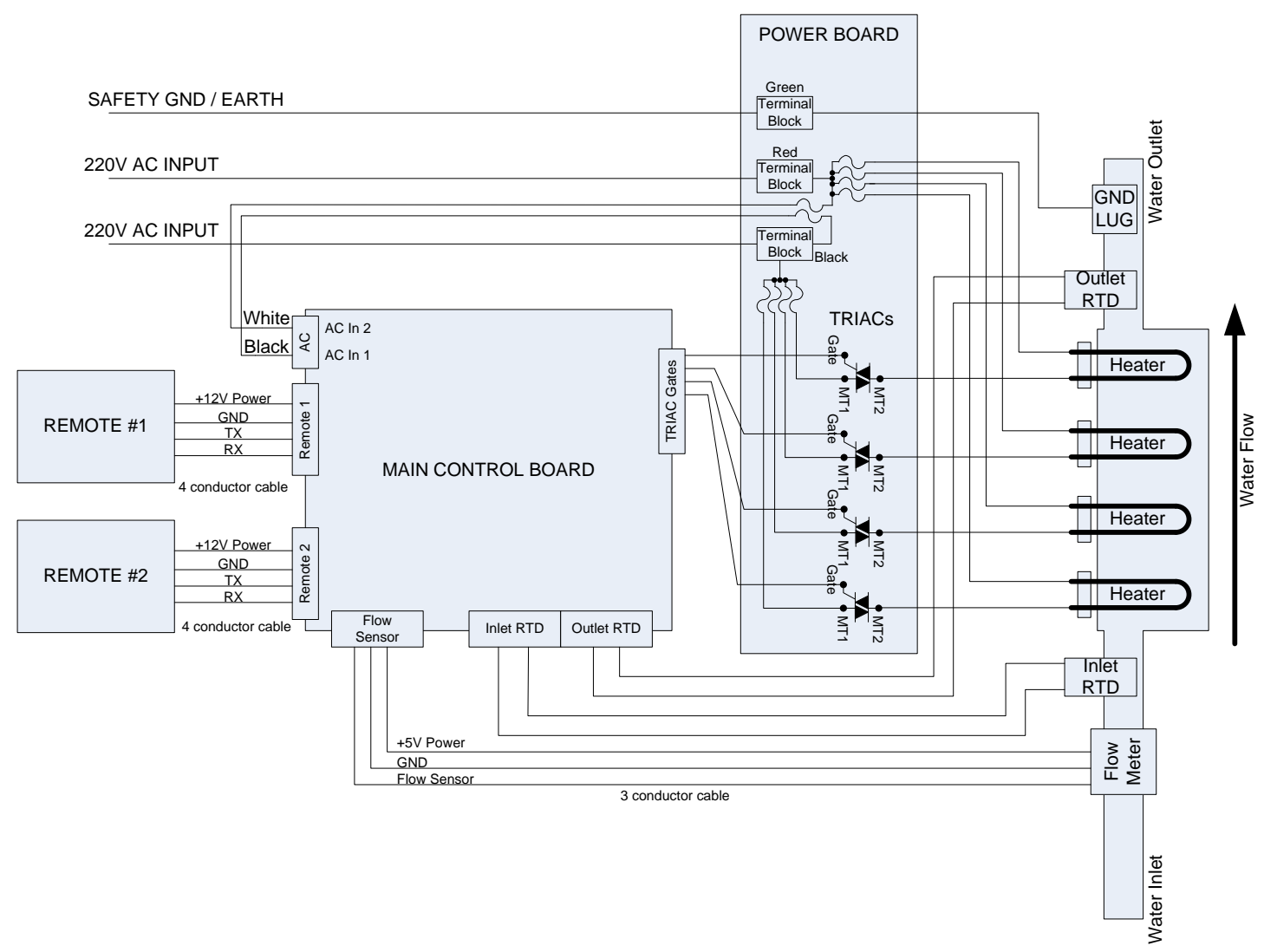

Figure 24: Schematic design of electrical system

\subsubsection{Heat Exchanger}

Since the control performance is affected by the heat exchanger (volume of water in tubes, thermal mass of system, convection and mixing conditions caused by flow configuration, etc.) a holistic approach needed to be taken in developing the improved prototype. Furthermore, a secondary goal of this project is to develop an improved-control TWH without imposing a significant cost premium, so the heat exchanger design was modified during the project. A preliminary prototype is shown in Figure 25 with labels. 


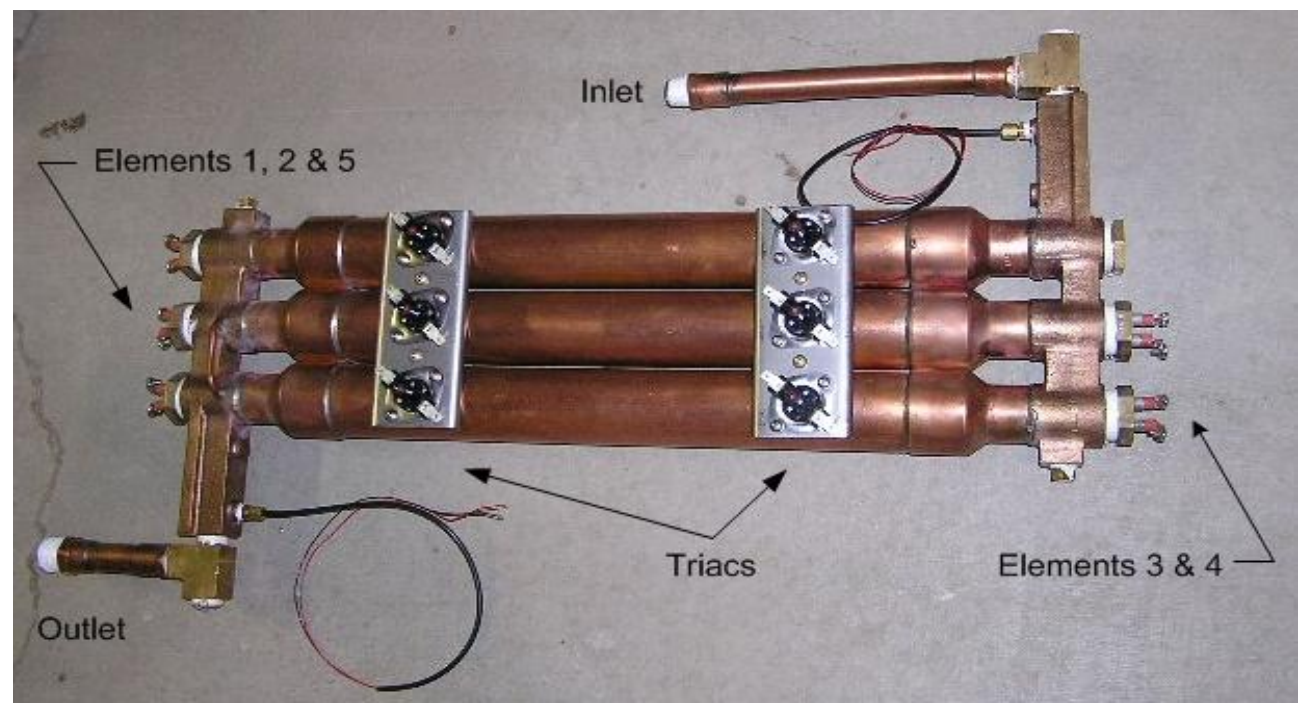

Figure 25: Preliminary prototype heat exchanger

The flow is in a serpentine configuration. Cast bronze headers in the preliminary prototype were costly and added thermal mass to the system. Also, they were not scalable. The final prototype has a modular design so that any number of passes can be connected (each with a $7.5 \mathrm{~kW}$ heater). It is not shown here because of proprietary technology belonging to Keltech.

Part of the rationale behind developing a modular design came from the DOE Peer Review of this project. The reviewers felt it was important that the application of the results of this project be available for booster heaters for solar and heat pump water heaters. The booster's power requirements can vary significantly, suggesting that a modular design would best address this requirement.

Another issue stemming from the peer review was that this project's results should be ready to apply to point-of-use water heaters, because they have the potential to save a great deal of energy. The reason is that distribution losses are significant, wasting typically at least $10-20 \%$, and often $50 \%$ of total water heating energy [ASHRAE 2007; Baskin et al. 2004; Hiller 2005]. These losses apply whether the water heating system is high efficiency, solar, heat pump, condensing gas combustion, etc. However, these losses are not present (or are minimal) with point-of-use heaters. In most cases electric resistance is the only practical alternative for point-of-use heaters. In light of this, we continually made sure that the approach for this project will apply to point-of-use heating, including the use of a modular design.

\subsubsection{Microcontrollers}

Two separate, but communicating controllers are used in the final product: the main board and the remote board(s). 


\subsubsection{Main Board}

The system shown in Figure 24 has a "Main Board", which contains the microcontroller that runs the control program, receives input from the sensors, sends output signals to the TRIACs, and communicates with the remote boards. The remote board prototype that was developed is shown in Figure 26 below. The printed circuit board (PCB) is labeled with the various inputs and outputs. A temperature unit switch (to display ${ }^{\circ} \mathrm{C}$ or ${ }^{\circ} \mathrm{F}$ ) is configurable by the assembler (not user). Some resistors and LEDs on the right were being used for testing when the photo was taken.

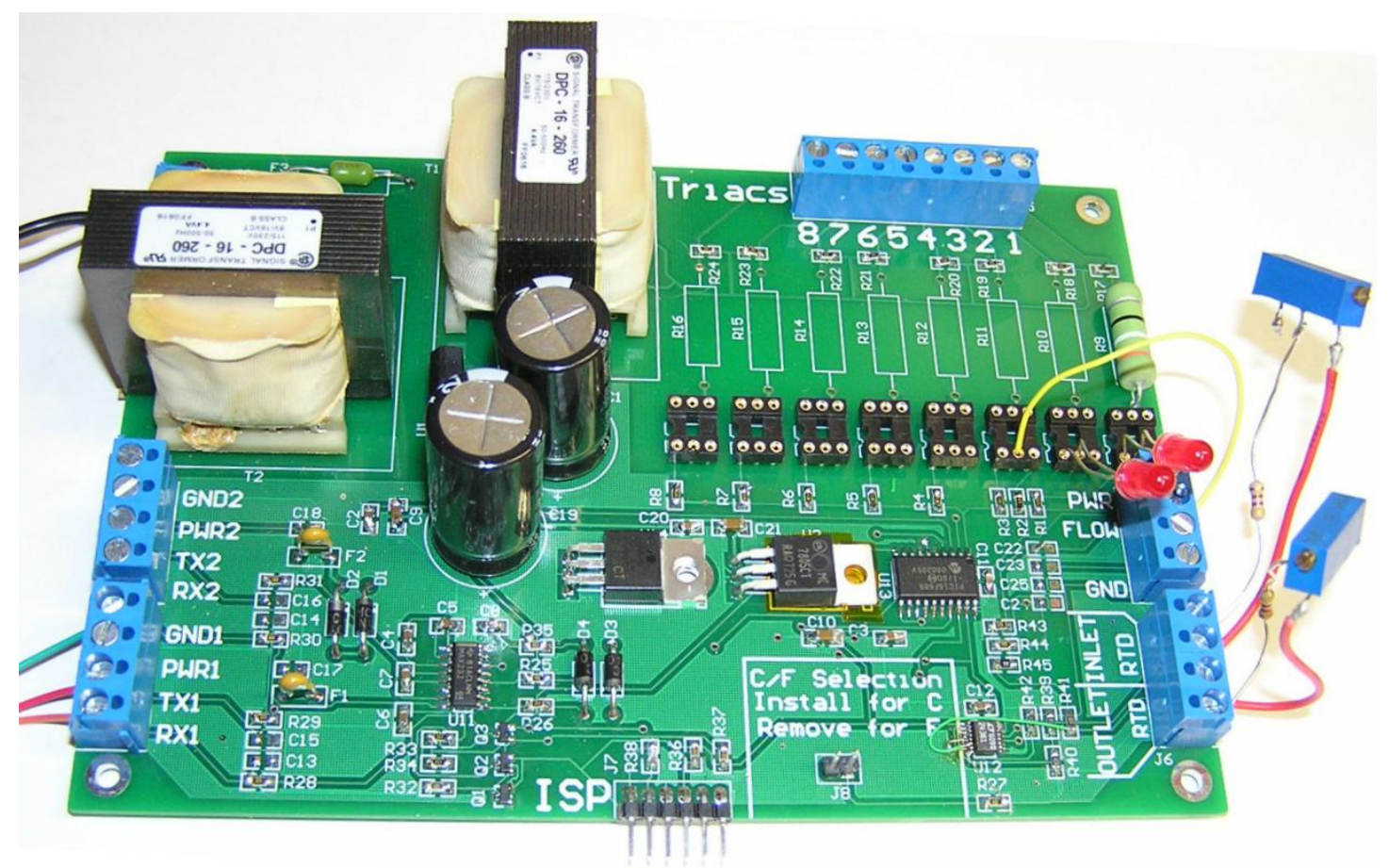

Figure 26: Main board prototype

This main board connects via a serial communication connector (on the left) to the remote board(s). The microprocessor can be programmed by connecting to a computer via the 6 pin ISP connection at the bottom center of the photograph.

\subsubsection{Remote board}

One or two remote boards connect to the main board. The remote boards contain the user interface. One is normally located on the unit's cover. The second optional remote board can be located in a bathroom, kitchen, or some central location. This second board can be wired or wireless. The prototype remote board is shown below, in Figure 27. The front has labels silkscreened on it to correspond with the button switches that will be put there: Flow Rate, Inlet Temp, Outlet Temp, Up, 
and Down. The latter two are used to change the outlet temperature setpoint. The first three control which quantity is shown on the display. If no button is depressed, the display shows the temperature setpoint.

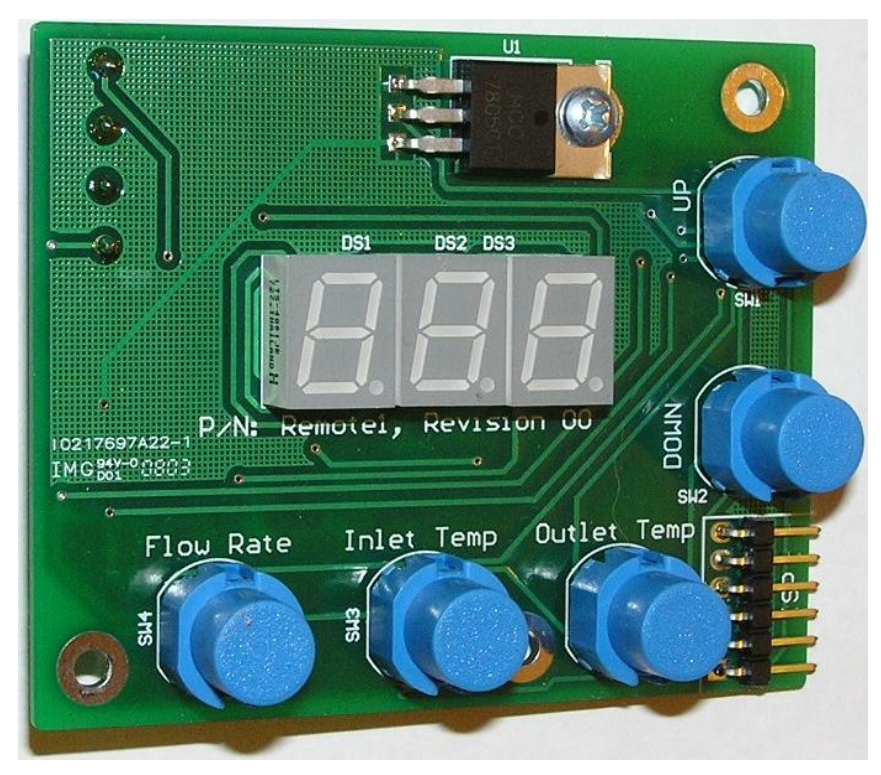

Figure 27: Remote board

\subsubsection{Sensors}

Inlet and outlet temperature are measured using RTDs. These sensors are unchanged from the currently existing heater (except that there are two instead of one).

Flow rate is more challenging to measure, for several reasons. Flow sensors can be very expensive depending on the sensor type and desired accuracy. They must be able to handle water with varying impurities and often carrying sediment without losing accuracy over time. They must give signals quite rapidly. The final selection for a flow sensor is a Hall-effect turbine sensor. This sensor is custom manufactured to have additional magnets to give higher frequency signals.

The accuracy of this production sensor was compared with our laboratory-grade sensor. The production sensor gives periodic pulse signals to indicate flow rate. The main board has signal conditioning algorithms programmed into it to interpret the periodic pulse signals being received and translate them into a flow rate. Figure 28 shows the comparison of the two sensors; the production sensor behaves extremely well, showing excellent repeatability even in the low flow range (below its specified range). 


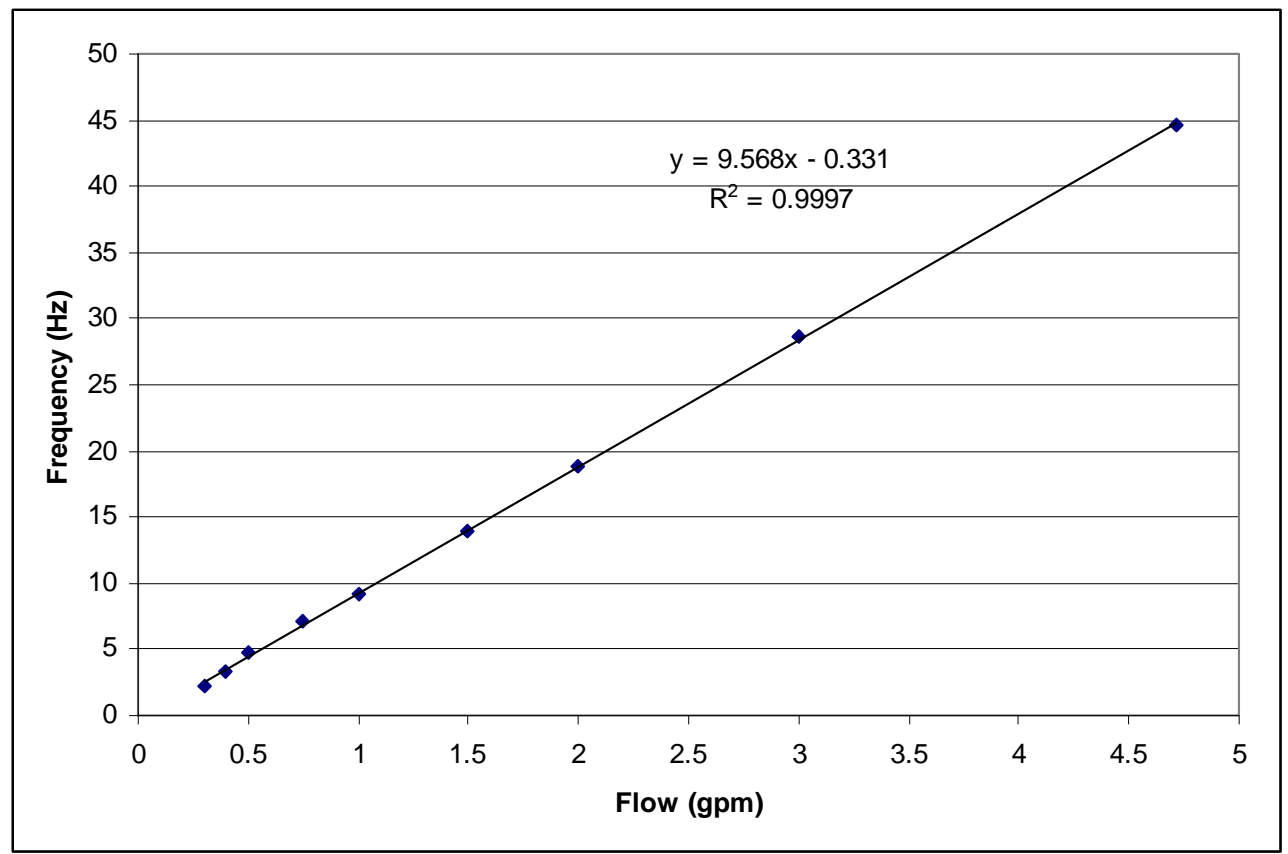

Figure 28: Comparison of production and laboratory flow sensors

\subsubsection{Packaging}

The new heaters have been repackaged because of the changes to all of their components. The design of the new packaging is complete, and an electronic rendering is shown below in Figure 29, with cover and without cover. The new design accommodates the flow sensor's requirement of a straight length of pipe, uses a small loop of unheated water to cool electronic components, and supports the new modular header design. The prototype model has a $30 \mathrm{~kW}$ capacity, which is sufficient for whole-house water heating for a large portion of houses in the US.

An unusual feature of the unit's design is that it uses internal fusing for overcurrent projection, rather than using the circuit breakers in the electrical panel. If the unit was not internally fused the heating elements would need to be on individual $30 \mathrm{Amp}$ breakers. Using multiple breakers would typically increase the installation cost, whereas using internal fusing increases the manufacturing cost. Keltech's belief is that the option with the lowest cost for the consumer - combined cost of installation and manufacture - is the best choice, hence their decision to internally fuse. This is rare or perhaps unique in the electric TWH currently on the market. 


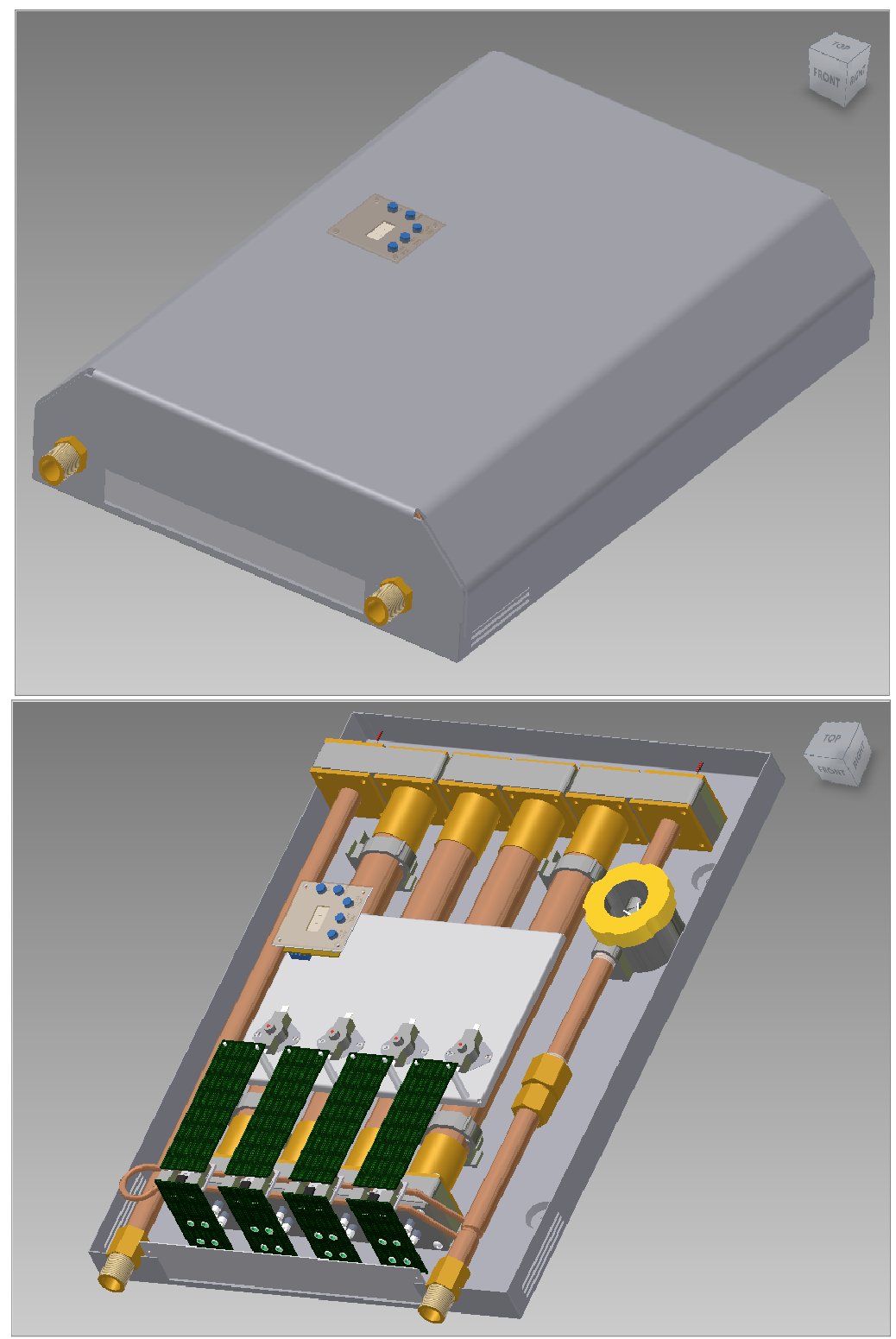

Figure 29: Heater packaging design 


\section{Project Administration}

\subsection{Budget}

The project was completed within the budget allocated by the cooperative agreement. No additional funding was requested. A breakdown of how the budget was allocated by category in the cooperative agreement is shown below in Table 6. The actual expenditures for the project are shown in Table 7.

Table 6: Total approved budget proposed

\begin{tabular}{lrrr} 
& Federal & Non-Federal & Total \\
\cline { 2 - 4 } a. Personnel & 137361 & 2039 & 139400 \\
b. Fringe Benefits & 0 & 0 & 0 \\
c. Travel & 8050 & 98 & 8148 \\
d. Equipment & 12124 & 0 & 12124 \\
e. Supplies & 986 & 14 & 1000 \\
f. Contractual & 53590 & 87399 & 140989 \\
g. Construction & & & 0 \\
h. Other & & & 0 \\
i. Total Direct Charges & 212111 & 89550 & 301661 \\
j. Indirect Charges & 152470 & 2264 & 154734 \\
k. TOTALS & $\mathbf{3 6 4 5 8 1}$ & $\mathbf{9 1 8 1 4}$ & $\mathbf{4 5 6 3 9 5}$
\end{tabular}

Table 7: Actual expenditures

\begin{tabular}{lrrr} 
& \multicolumn{1}{c}{ Federal } & Non-Federal & \multicolumn{1}{c}{ Total } \\
\cline { 2 - 4 } a. Personnel & 149043 & 0 & 149043 \\
b. Fringe Benefits & 0 & 0 & 0 \\
c. Travel & 4429 & 0 & 4429 \\
d. Equipment & 15248 & 0 & 15248 \\
e. Supplies & 3442 & 0 & 3442 \\
f. Contractual & 29183 & 152788 & 181971 \\
g. Construction & & & \\
h. Other & & & \\
i. Total Direct Charges & 201345 & 152788 & 354133 \\
j. Indirect Charges & 163236 & 2202 & 165438 \\
k. TOTALS & $\mathbf{3 6 4 5 8 1}$ & $\mathbf{1 5 4 9 9 0}$ & $\mathbf{5 1 9 5 7 1}$
\end{tabular}

\subsubsection{Differences between proposed and actual expenditures}

The approved budget in the cooperative agreement included non-federal cost sharing of $20 \%$ of the total project cost. During the project additional opportunities for improvement presented themselves, 
and Keltech became increasingly committed to the project. These opportunities increased the scope of work for Keltech and for BSI.

Keltech increased their effort in the project from $\$ 87 \mathrm{k}$ to $\$ 153 \mathrm{k}$ - a $75 \%$ increase. This brought their total cost sharing portion to $30 \%$. It also illustrates their commitment to the goals of this project.

BSI was constrained by a finite budget so we made several adjustments to complete the original tasks and the additional opportunities within the approved total budgeted amount of $\$ 365 \mathrm{k}$. For example, we found that during the execution of the project tasks we had developed sufficient in-house expertise that some of the work intended to be subcontracted could be completed in-house. Since our rates are quite low, this reduced the cost of these portions of the work. Thus the personnel costs, line a, increased and the federal portion of contractual costs, line $f$, decreased. In addition, our subcontractors, Dr. Gregor Henze and Mike Coward, kindly agreed to substantial increases in scope without increasing their fees.

\subsection{Schedule}

This project was originally planned to be completed in a two-year period, from 07/01/05 to 6/30/07, but a no-cost extension of an additional year was required, with the project ending 6/30/08. There were numerous unexpected setbacks in the project that required additional time, but these are present in almost every research project and to some extent they had been budgeted for. The most significant delays were caused by the following

1. No existing method of test for tankless water heater control performance. We had anticipated that a literature review would reveal some reference to an approach to measure temperature control in TWH or in a similar application. We planned adapt this reference to be used in a temperature control method of test for TWH, but none was discovered so we had to fully develop the method of test and apparatus to conduct it.

2. Modified approach to controller testing and development platform. At the suggestion of subcontractor Dr. Gregor Henze the rapid prototype development platform was built. This improved the quality of the final product because it allowed rapid assessment of different approaches combined with different microcontroller hardware. However it took a great deal more effort that the original plan, which was to develop the control entirely in the simulation environment, subcontract the selection and programming of a microcontroller, and install the microprocessor into the prototype heater. The rapid prototype development encountered problems in software compatibility and with software bugs. It stalled the project for six months before it worked for the first time. However, once it worked it was used to test hundreds of possibilities whereas the original plan would have allowed only a few to be tested. 
3. Health problems with manufacturing partner. Ken Lutz, founder and chief technical engineer at Keltech suffered a serious heart problem and was away from work for three months, before returning to work for only a few hours per week. Mr. Lutz is our main contact at Keltech, and is responsible for all new product development there. Although we continued to work on the project while he recuperated we weren't able to proceed at a full pace because some decisions needed to be made by the manufacturer who will be using the results in his product for many years.

4. Other increases to scope. There were several opportunities that presented themselves, as mentioned above, that could greatly increase the usefulness of the project's results. These also tend to increase the scope of work. One example is the testing of additional control approaches besides MPC. This had not been planned but it turned out to produce some of the most powerful results of the project, because it showed that a simpler alternative control method can provide results comparable to the highly complex MPC. Such increases to scope increased the time required to complete the project. 


\section{Final Results}

\subsection{Product}

The central result of this project is a new Keltech heater that will be marketed starting in spring of 2009. This heater is shown in Figure 29. It will be the premier electric TWH, with the best control performance of any consumer TWH available, robust components, compact size and sold in the mid-market price range.

\subsection{Objectives and outcomes}

This project was very successful in achieving its goals and in providing unanticipated positive outcomes. Table 1 gave a list of criteria for success. Table 8 compares these criteria with the actual outcomes of the project. A brief discussion of these criteria and the outcomes follows the table.

Table 8: Objectives and outcomes

\begin{tabular}{|c|c|c|}
\hline Objective & Criterion for success & Outcome \\
\hline Develop a test method & $\begin{array}{l}\text { Ability to quantify control } \\
\text { performance }\end{array}$ & A MOT was developed and refined \\
\hline Develop a rating system & $\begin{array}{l}\text { Ability to meaningfully quantify better } \\
\text { performance }\end{array}$ & $\begin{array}{l}\text { Developed a system using the ISE } \\
\text { criterion for } 11 \text {-test set }\end{array}$ \\
\hline $\begin{array}{l}\text { Develop an improved TWH } \\
\text { controller }\end{array}$ & $\begin{array}{l}\text { A working controller that improves } \\
\text { control }\end{array}$ & $\begin{array}{l}\text { New controller gives far better control } \\
\text { and other benefits }\end{array}$ \\
\hline $\begin{array}{l}\text { Include controller in } \\
\text { manufacturable prototype }\end{array}$ & $\begin{array}{l}\text { A prototype that is ready for mass } \\
\text { production }\end{array}$ & $\begin{array}{l}\text { Done. Prototype heater was also } \\
\text { improved }\end{array}$ \\
\hline Impose minimal cost premium & Increase overall cost by $<5 \%$ & Cost was not increased at all \\
\hline Disseminate results & $\begin{array}{l}\text { Published papers or public } \\
\text { presentations }\end{array}$ & Multiple papers and presentations \\
\hline
\end{tabular}

The development of a test method may be one of the most important results of this project. The reason is that the test method can help usher in better temperature control throughout the industry by helping manufacturers assess their control performance, know where improvements are needed, and quantify the improvement (or damage) caused by changes to their approach. Furthermore, if the method of test and rating system developed in this project lead to a rating standard for consumers, this will encourage all TWH manufacturers to improve control. Once good control is standard in TWH, a significant barrier to widespread adoption will have been removed. 
The controller developed in this project uses the Feedback-Compensated Feed-Forward control algorithm described earlier. Its control performance is vastly improved, as was shown in Table 5 . The results in Table 4 are for the $18 \mathrm{~kW}$ development model, but the final production model is a $30 \mathrm{~kW}$ model. The ISE results of this unit are given in Table 9 below. Unfortunately, ISE results by themselves do not give a very good comparison for different sized heaters. For example, a larger heater holds a larger volume of water, typically, and will produce a larger plug of cool water before the heated water enters the supply pipe. The cold start tests (5-7) will, therefore, give higher ISE values for larger heaters. A system could be devised to normalize across sizes to give reasonable comparisons. This is discussed further under "Future Work". Regardless, the results below indicate excellent temperature control.

Table 9: ISE results for final (production model) $30 \mathrm{~kW}$ TWH

\begin{tabular}{c|cc|c|}
\cline { 2 - 4 } Test \# & \multicolumn{2}{|c|}{ Flow Rate $[\mathrm{L} / \mathrm{min}]$} & ISE \\
& Initial & Final & {$\left[\mathrm{K}^{2}\right.$-s $]$} \\
\cline { 2 - 4 } 2 & 3 & 12 & 247 \\
2 & 12 & 3 & 680 \\
3 & 6 & 12 & 117 \\
4 & 12 & 6 & 152 \\
5 & 0 & 3 & 12221 \\
6 & 0 & 6 & 6274 \\
7 & 0 & 12 & 4653 \\
\hline
\end{tabular}

\begin{tabular}{c|c|c|}
\cline { 2 - 3 } & $\begin{array}{c}\text { Step } \\
{\left[{ }^{\circ} \mathrm{C}\right]}\end{array}$ & $\begin{array}{c}\text { ISE } \\
\mathrm{K}^{2}-\mathrm{S}\end{array}$ \\
\cline { 2 - 3 } 8 & 5 & 13 \\
9 & -5 & 14 \\
10 & 15 & 83 \\
11 & -15 & 50 \\
\cline { 2 - 3 } & \multicolumn{3}{|c|}{ Total } & 24504 \\
& &
\end{tabular}

An additional successful outcome for the project is the finding that the Feedback-Compensated FeedForward control approach can provide superior control. This approach is simple enough for most manufacturers to use, so it is likely to be adopted by many manufacturers once the results of this project are disseminated through the technology transfer activities described later in this report.

The new controller gives additional benefits besides improved control:

1. Several fault detection and diagnosis routines have been programmed into the controller to increase safety and ease repair. The specifics of these routines are considered proprietary by Keltech.

2. The TRIAC control uses a proprietary routine that was devised to spread the electric load evenly over time to avoid "flicker factor" - the flickering of lights caused by rapid variations in system voltage, which is a common problem in electric TWH (or other large switched electric loads). 
3. The controller has been configured to allow two user-interfaces, so that a remote secondary user interface may be placed in a location near an end-use, such as in a bathroom.

We had assumed that the cost would increase for the improved controller. However, through careful design and component selection the cost of the production line of heaters is roughly the same as the previous generation, which used analog controls, and may be slightly less when bulk pricing of components is finalized.

The dissemination of results is discussed under "Technology Transfer", below.

\subsection{Technology Transfer}

\subsubsection{Papers}

A paper [Henze 2009] on the results of this project will be published in HVAC\&R Research on January 2, 2009. This paper discusses the use of Model Predictive Control for TWH.

A second paper is in progress and will be submitted in January. This paper describes the alternative control approaches tested in this project, and the results of the tests.

A third paper will describe the development of a method of test for temperature control of TWH, and the design of the test system. This paper is not yet in progress.

A fourth paper is planned; an engineering overview of TWH technology. This is intended for a broader but still technical audience, such as ASHRAE Journal, Engineered Systems, etc.

\subsubsection{Presentations}

"Improving Temperature Control in Electric Tankless Water Heaters," Seminar at ASHRAE in Dallas, Winter 2007 by Gren Yuill

"A Method of Test for Tankless Water Heater Temperature Control Performance," Seminar at ASHRAE in Dallas, Winter 2007 by David Yuill

"A Comparison of Advanced Control Methods for a Thermal Process," seminar to be proposed by David Yuill for ASHRAE Annual meeting, Louisville, KY, 2009.

"Applying Model Predictive Control," seminar to be proposed by Gregor Henze for ASHRAE Annual meeting, Louisville, KY, 2009. 


\subsection{Future work}

Several ideas for future work that would benefit the US have presented themselves during the execution of this project.

\subsubsection{Refinement of the test method to a standard method of test}

This would include a weighting system to give the ISE scores for each test different weights, depending on how important each test is to the comfort and safety of users. Then, the weighted scores should be combined in such a way that a simpler single number, or perhaps alpha-number rating could be expressed for laypersons (particularly consumers). It would also include a way to scale the overall scores for different sized heaters so that the same rating system could be used regardless of the heater size.

Finally, it would be prudent to conduct some temperature control performance tests on gas-fired tankless water heaters. All of the performance testing conducted so far has been for electric heaters. Gas TWH may present some unanticipated artifact of control that should be taken into account before the rating system is developed. The method of test and rating system should cover all TWH regardless of energy source, so that consumers can make fair comparisons.

The publication of a standard and rating system would encourage and allow manufacturers to improve control of their heaters. This, in turn, would help foster the adoption of TWH in the USA. ASHRAE has members that are interested in developing this standard when the necessary work is complete. The method of test also may be used by the Energy Star program as a rating criterion.

\subsubsection{Peak power issues}

Two issues related to peak electrical power usage suggest further work.

\subsubsection{Development of a current transformer load-shedding device}

One significant barrier to adoption of electric TWH is the large power requirement. The power drawn by a TWH is often greater than all other electric appliances combined. It means that larger electrical panels and conductors are required. During this project we conceived of an idea to include with the TWH a current transformer (CT) that would send a signal to the TWH controller. The CT would monitor wholehouse power and when the signal got to a maximum value (such as $190 \mathrm{Amps}$ for a $200 \mathrm{Amp}$ panel) the TWH would attenuate its power to avoid exceeding the maximum.

The effect would be that during the rare occasion when, for example, the air-conditioning is running, electric stove is in use, electric dryer is running, and two simultaneous showers are being taken, the water in the showers would get cooler until the air-conditioning cycled off or one shower stopped, etc. 
The TWH is an excellent candidate for load shedding because it can be attenuated and because it is a large user that would likely be able to reduce power sufficiently with a single piece of equipment.

We began to proceed with development of this product, but a patent search showed that a TWH manufacturer has already patented such a device. Regardless of intellectual property rights, it would be useful for this product to be available in the marketplace, particularly if it can be used for multiple manufacturers' TWH.

\subsubsection{Utility Peak Power Concerns}

We have met with representatives from some large electrical utilities during this project who have voiced concerns over widespread adoption of TWH. Their fear is that transformers will be overloaded by high demand during the morning peak (when many homeowners are showering). Even if the transformer's peak capacity is not exceeded, coming near to this capacity frequently reduces the life of the transformer.

A study by Johnson and Clark (2006) showed that it requires very little diversity for TWH to give the same peak load profile as storage heaters. Their study monitored one house that switched between electric storage and TWH heater on a weekly basis for several months. They superimposed the instantaneous power data from multiple days to simulate multiple homes on a single day. This would likely give a less diverse profile than if multiple homes were monitored, because the morning routine in a single home is likely to repeat more exactly (showering at the same time every day). It would be useful to conduct a similar study to Johnson and Clark's but with a larger number of houses and more rigorous measurement approach. The results would allow utilities to assess potential benefits and costs of widespread TWH adoption, and to consider solutions to any anticipated problems.

\subsubsection{Gas TWH control performance}

Anecdotal evidence suggests that some gas TWH experience similar control problems to electric TWH. Measurement of a small number of gas TWH would show the extent of the control difficulty. If similar control problems exist in gas TWH as in electric TWH the results of the current project could be adapted to apply to gas TWH, which constitute a larger portion of the market than electric. This would leverage the successes of the current project to reach a broader market. 


\section{References Cited}

ASHRAE, 2007. HVAC Applications Handbook. Chapter 49.

Baskin, E., R. Wendt, R. Lenarduzzi, and K. A. Woodbury, 2004. Numerical Evaluation of Alternative Residential Hot Water Distribution Systems. ASHRAE Transactions, Vol. 110 Issue 2, pp. 671-681.

Haissig, C.M., and M. Woessner, 2000. An Adaptive Fuzzy Algorithm for Domestic Hot Water Temperature Control of a Combi-Boiler. HVAC\&R Research, 6(2): 117-134.

Herrmann, C., V. Candas, A. Hoeft, and I. Garreaude, 1994. Humans Under Showers: Thermal Sensitivity, Thermoneutral Sensations, and Comfort Estimates. Physiology \& Behavior, Vol. 56, No. 5, pp. 10031008.

Henze, G.P., D.P. Yuill, and A.H. Coward, 2009. Development of a Model Predictive Controller for Tankless Water Heaters. HVAC\&R Research, Vol. 15, No. 1.

Hiller, C.C., 2005. Comparing water heater vs. hot water distribution system energy losses. ASHRAE Transactions 111(2): 407-417.

Johnson, R.K., and C.A. Clark, 2006. Field Evaluation of Two Demand Electric Water Heaters. ASHRAE Transactions, 112(1): 426-435.

Maciejowski, J. M., 2002. Predictive Control with Constraints. Pearson Education POD.

Ohnaka, T., Y. Tochihara and Y. Watanabe, 1994. The effects of variation in body temperature on the preferred water temperature and flow rate during showering. Ergonomics, 37(3): 541-6.

Rohles, F.H. and S.A. Konz, 1982. Showering behavior: Implications for water and energy conservation. ASHRAE Transactions, 88(1): 1063-1072.

U.S. Department of Energy, 2001. A Look at Residential Energy Consumption in 2001. Energy Information Administration. 